\title{
مدينة القد بين الحق التاريخي والحق القانوني
}

\author{
Jerusalem between the historical right and the legal right \\ 2019/05/06 :2019/05/30 : تاريخ الاستلام
}

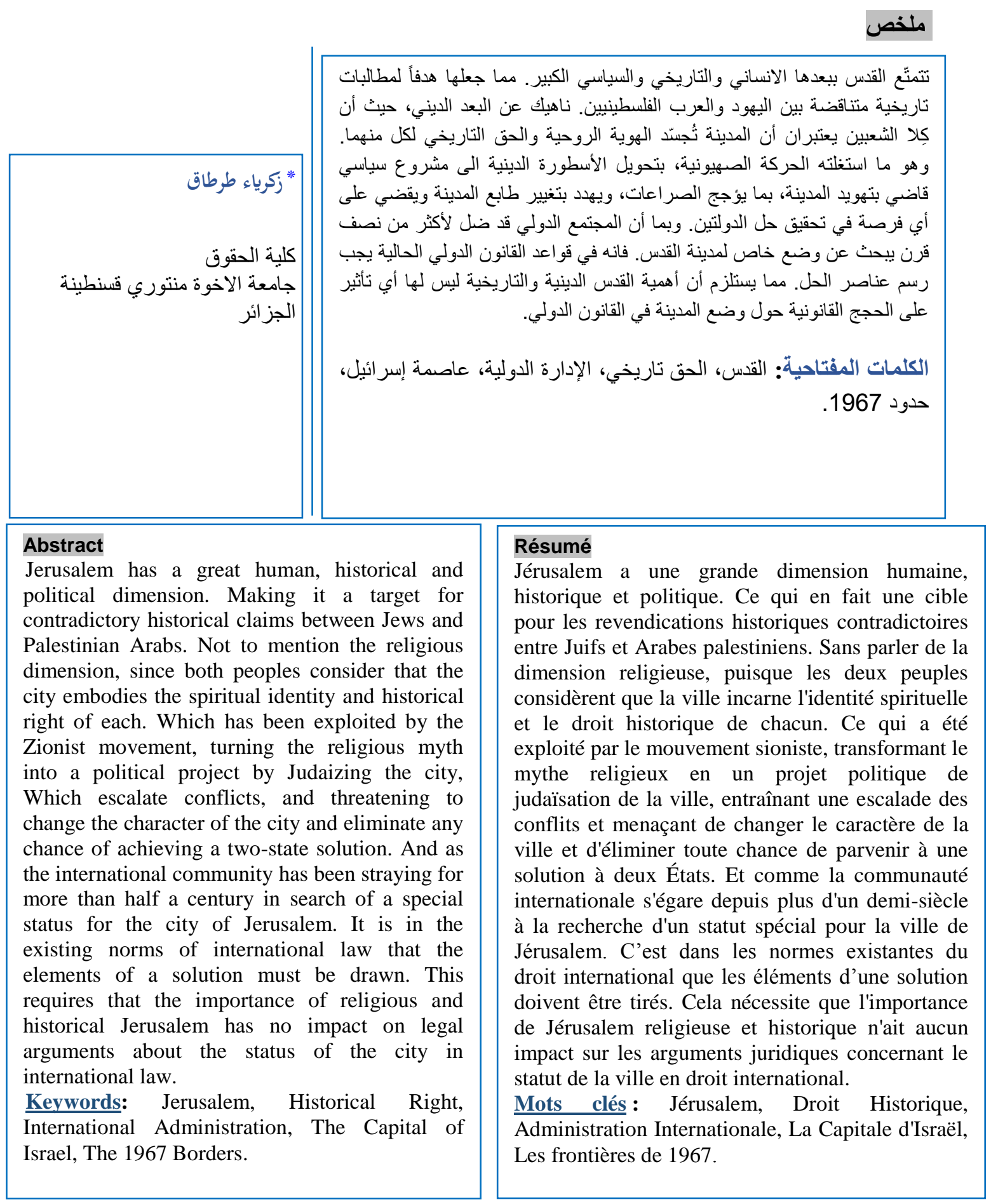

* Corresponding author, e-mail: zakaria.trtg@ gmail.com 
I

عدد قليل من المدن هي رمزية ومحل مطالبة مثل القس. بالنسبة لليهود في

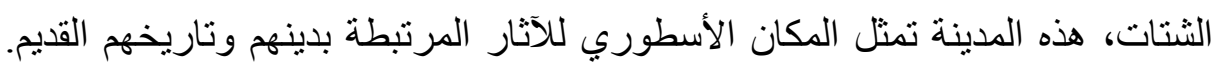

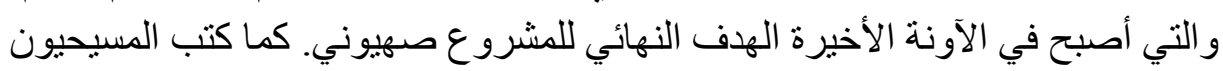

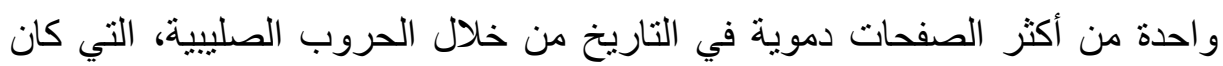
هدفها حماية مقبرة المسيح، وبالنسبة للعالم الإسلامي، وأبعد من دائرة دائرة الفلسطينيين

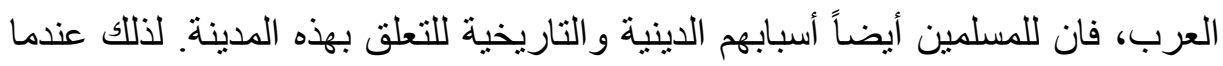

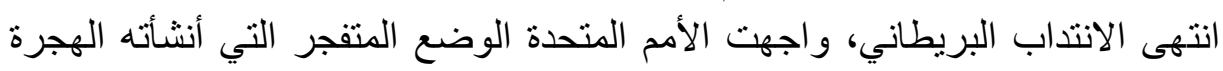

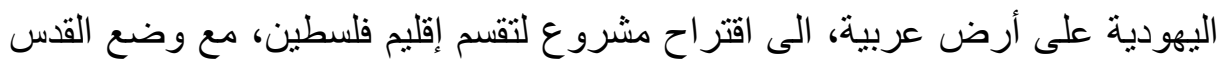

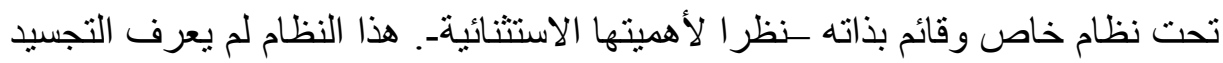

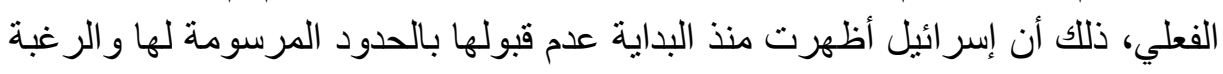
في الوصول الى القس، وقد كانت حرب القبل 1948، مناسبة لبداية التوسع الإقليمي

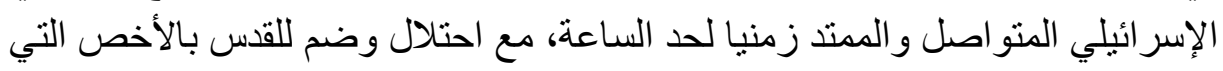
أعلن مؤخر ا عن أنها عاصمة أبدية للدولة اليهودية. هذا الاحتلال الإقليمي الذي الذي تمارسها

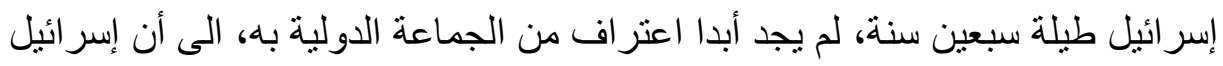

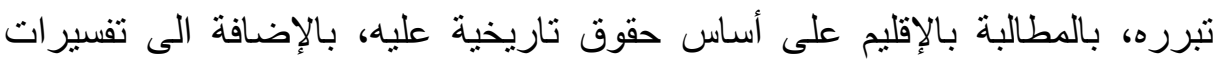
قانونية من منظور فقهي أحادي الجانب، مدعم بسياسة فرض الو اقع بالقوة العسكرية. سنحاول في هذا المقال تسليط الضوء على المركز القانوني للقدس من زاوية

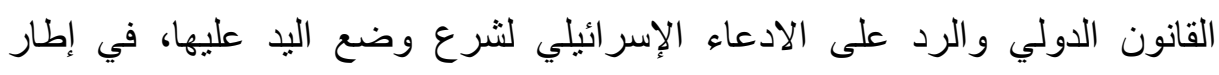

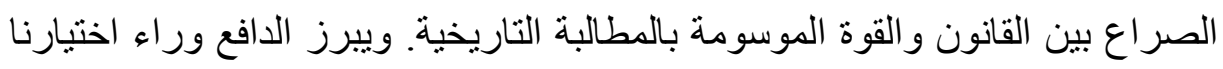
للموضوع في حداثثه باعتباره حديث الساعة على الساحة الدولية، وكدى أهية مدينة

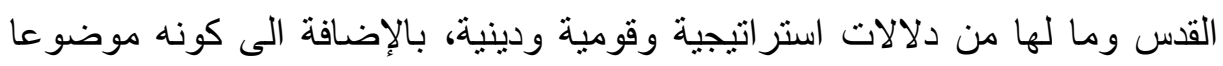

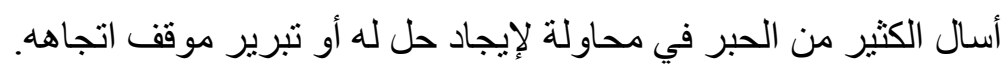

سنستعين خلال دراستنا بمختلف أدوات البحث العلمي، على غرار المنهج التاريخي و الاستدلالي و التحليلي و المقارن، و هذا للإجابة على التساؤل المركزي التئي التالي:

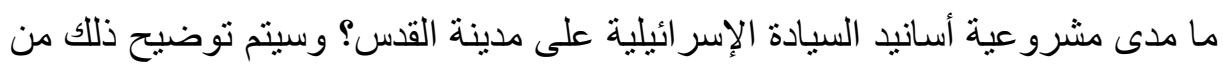
خلال النقاط المفرغة في الخطة التالية: المطلب الأول: الحق التاريخي على مدينة القس الفرع الأول: تاريخ المدينة الفرع الثاني: الحق التاريخي في القانون الدولي المطلب الثاني: القد كموضوع للقانون الدولي الفرع الأول: الإدارة الدولية لمدينة القس الفرع الثاني: القدس عاصمة الدولتين 
المطلب الأول: الحق التاريخي على مدينة القدس

تقع مدينة القس على خط طول 35 درجة و 13 دقيقة شرق خط غرينتش، وخط عرض 31 درجة و52 دقيقة شمالاً، وعلى سلسلة من التلال يتراوح الته ارتفاعها

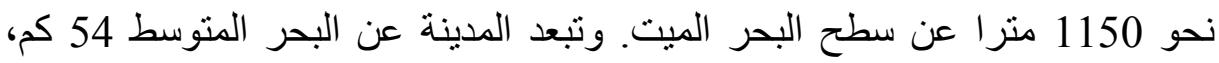
و عن البحر الأحمر 250 كم تقريباً. وترتبط القدس بكبريات المدن الفلسطينية وبعض العواصم العربية، فهي تبعد عن عكا 150 كم، وعن نابلس 65 كم، وعن وعن الخليل 36 كن

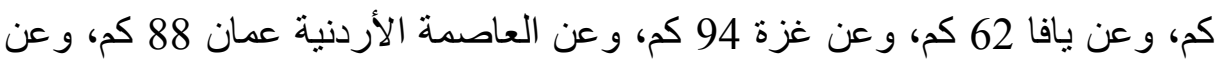
دمثق 290 كم، وعن القاهرة 528 كم، وعن بغداد 865 كم. و وتعتبر القدس مدينة

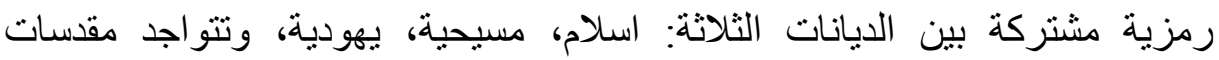
الديانات الثلاثة حاليا في (القدس القديمة)، والتي بدورها تتشكل من أربعة أحياء

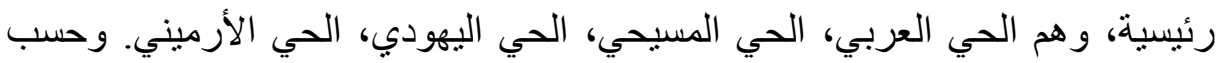
الباحثين فان مكانة القد بالنسبة للمسيحيين هي روحانية أكثر منها ارتباطا بالأرض،

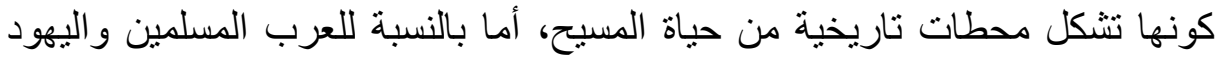
فدرجة الأهمية أكبر، وفي الآتي استعر اض لتاريخ المدينة والذي تشنترك في كتابته كلا الجماعتين.

\section{الفرع الأول: تاريخ المدينة \\ أولا: التاريخ اليهودي للمدينة}

تجد الصهيونية تبرير ها لاحتلالها فلسطين ككل على أسس دينية وتاريخية

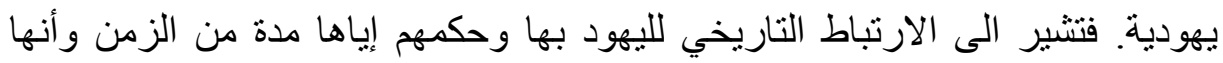

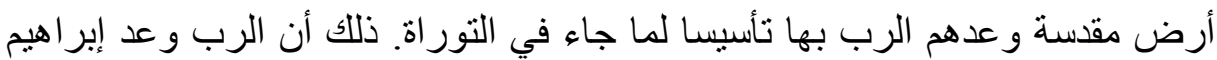

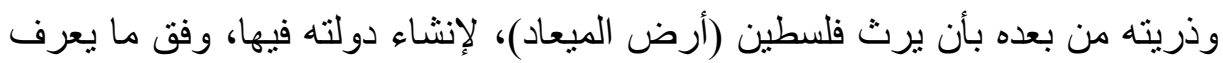

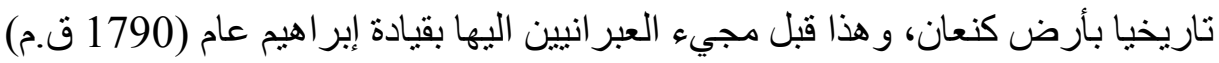

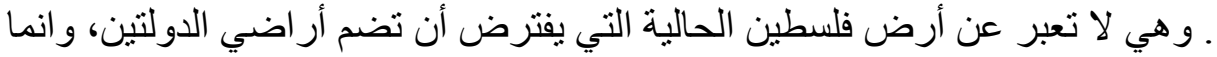

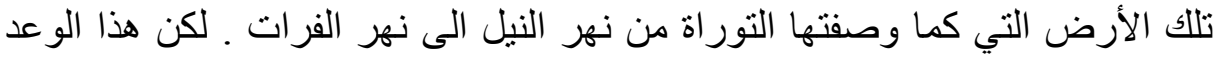
لابد بأن يعنى ببني إسرائيل وحدهم، لذى نجد في الفقه اليهودي أن حقهم الديني

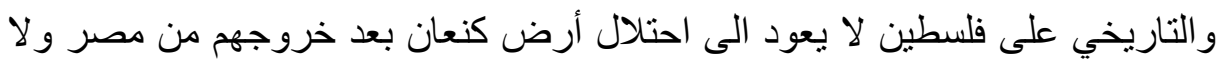

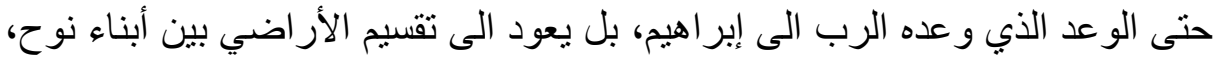

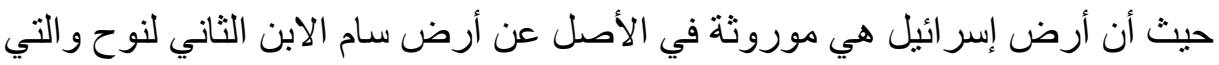

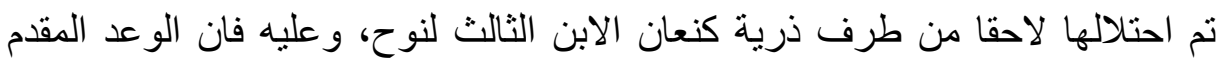

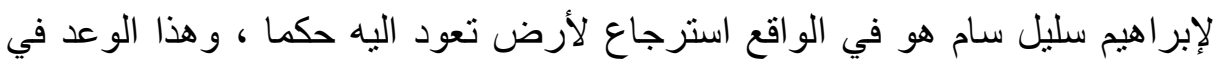

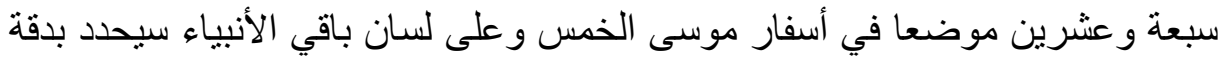

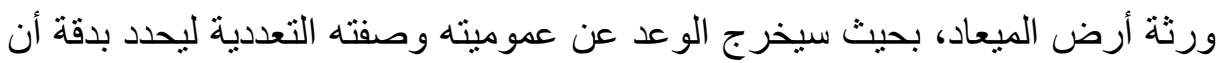
الفرع الوارث للأرض هو ابنه إسحاق ثم يعقوب الذي سيصبح اسمه إسر ائيل ـ و وعليه فان أرض الميعاد Terre Promise، أو أرض كنعان Terre De Canaan، أو أو أو أو أرض الأموريين Terre Des Amoriens، أو أرض العبرانيين Terre Des، . Terre (Eretz) D’Israël هي نفسها أرض إسر ائيل Hébreux 


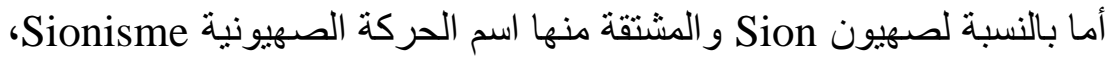
فتعني حسب المنظور اليهودي مدينة القس، وهي ليست مجرد مدينة لأنها معلم

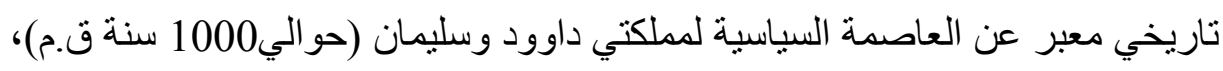
أيضا ومنذ الانفصال Le Schisme ، الى غاية الغزو البابلي (حوالي 586 ق.م) لمملكة يهوذا. كانت (القد) عاصمة لهاته الأخيرة تحت مسمى (أورشليم)

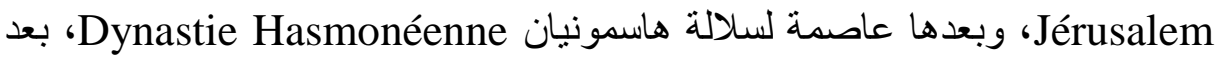

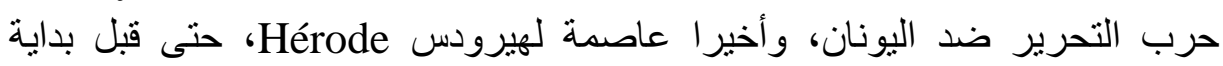

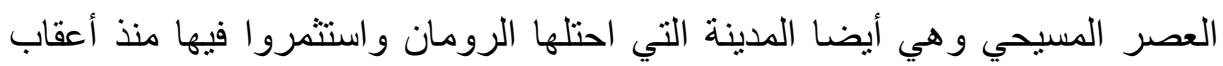

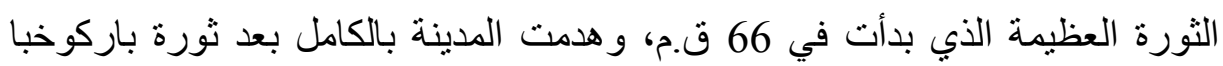
Bar Kokhba

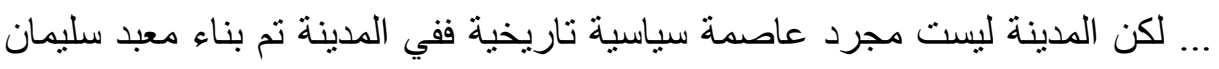

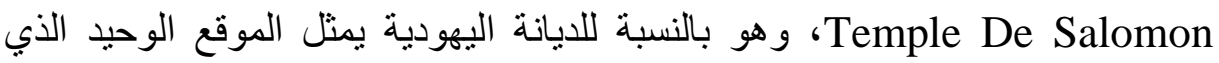

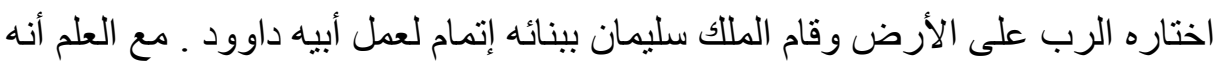

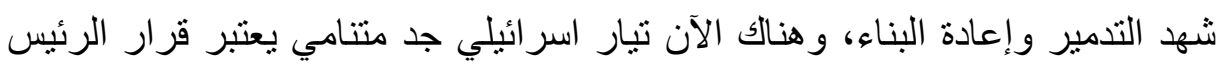

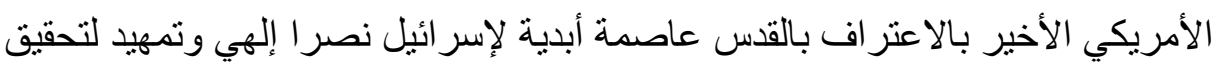

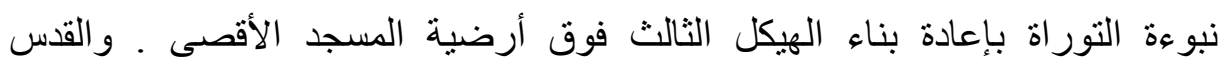

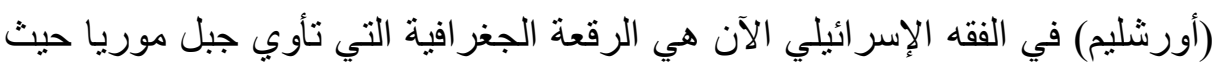

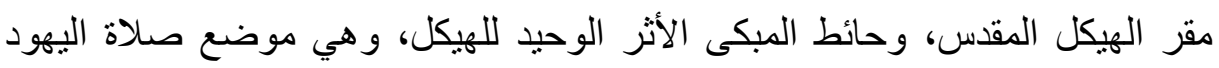

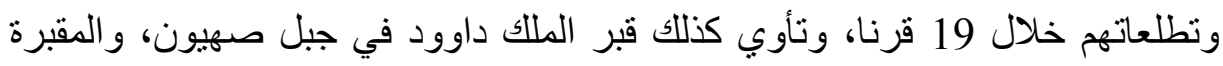

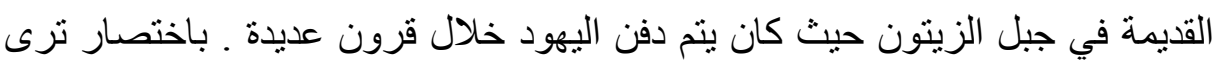

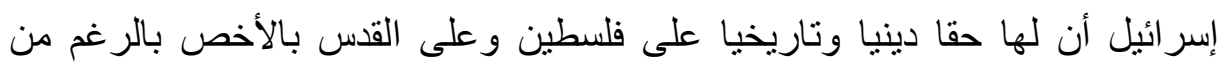

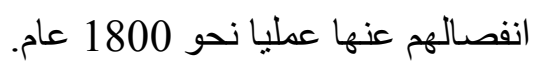

\section{ثانيا: التاريخ الإسلامي للمدينة}

ان أول اسم أطلق على القد هو يبوس، نسبة الى اليبوسيين الكنعانيين الذين

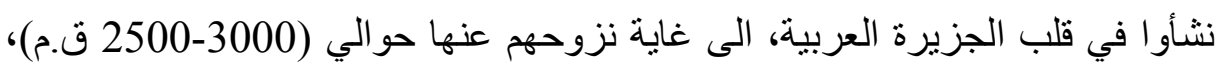
ويقال ان الملك سالم اليبوسي بناها وأقام تحصينها، لتعرف المدية نزوحة التهاينة باسمها الكنعاني (أورسالم) ـ فتسمية (أورشليم) التي يحاول الصهاينة اليوم عدها من الأسماء العبرية

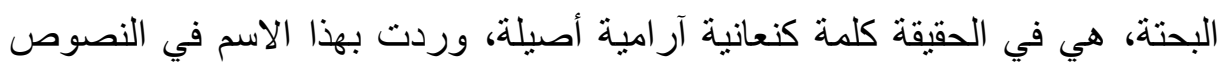

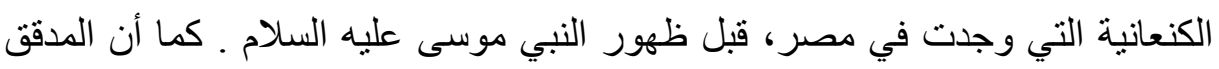

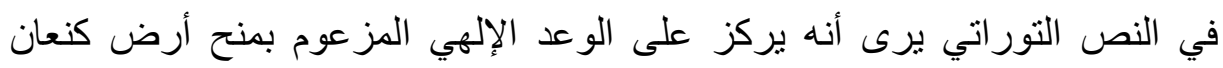

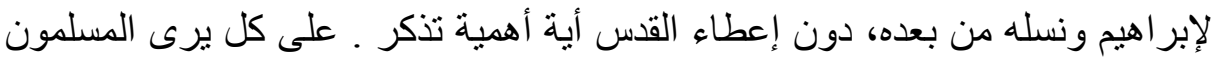

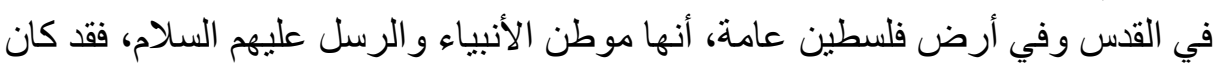

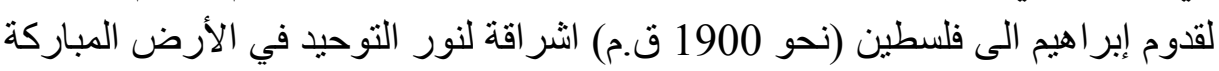

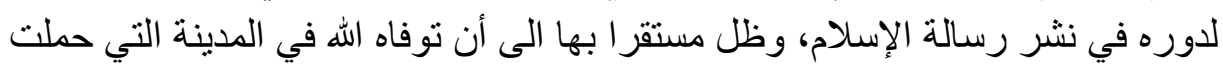
اسمه (الخليل)، وقد سار على دربه ابنه إسماعيل الذي سكن مكة و اسحاق و ابنه يعقوب 
الذين استقروا في فلسطين، وكان ليعقوب اثنا عشر ا ابنا هم الأسباط و المعروفون بيني

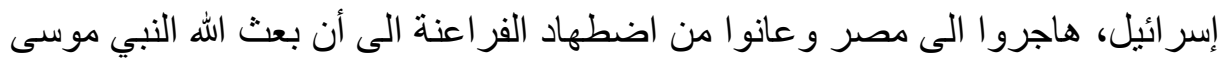

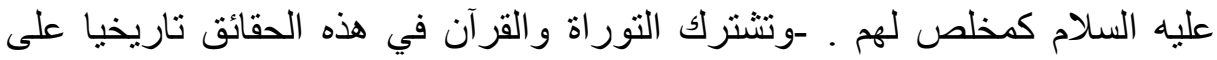
الأقل-.

ما تجدر الإشارة اليه في هذا السياق، هو أنه منذ أن فقد اليهود السيطرة على الئى فلسطين بمجيئ العصر المسيحي فان صلة العرب بها لم تنقطع فقد عرفت المناف المنطقة قيام

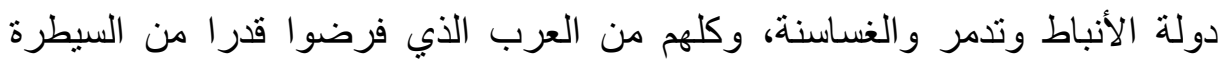
السياسية العربية على فلسطين في فترات متقطعة قبل الفتح الإسلامي. وكان لظهور

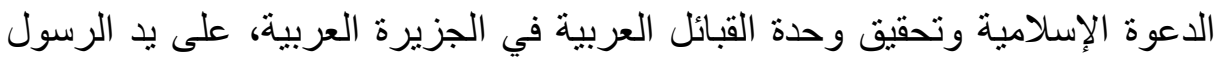

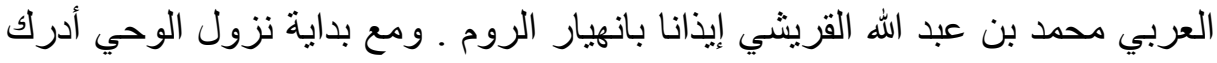

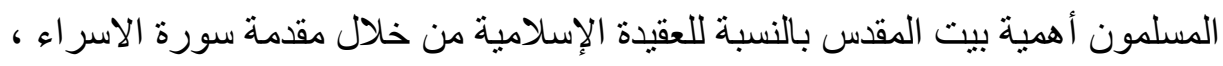
وفهموا أهمية الربط الإلهي بين المسجد الحرام والمسجد الأقصى وقدسيته ومسؤولية فتحه. وفي عام 636م، رفع علم العرب الإسلامي على بيت المقس (القدس) واستقبل

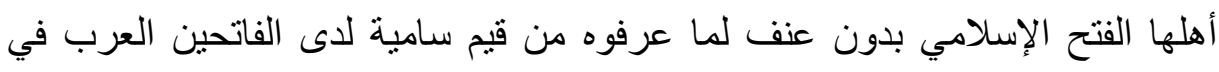

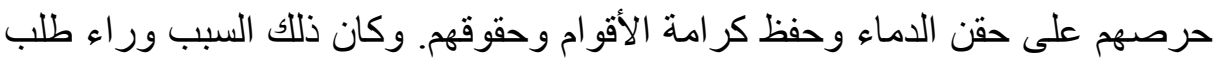

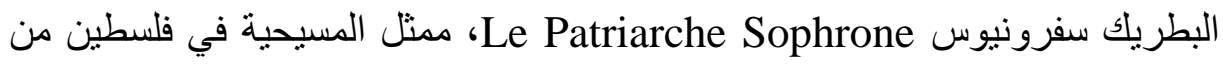
الخليفة عمر بن الخطاب أن يستأمن أهل ايلياء (القس) المسيحيين وأن يمنع دخول

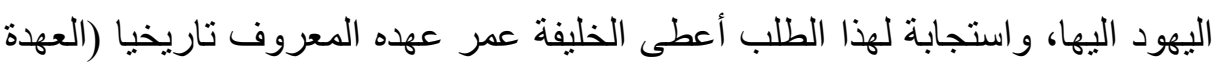

ولكون المدينة تعتبر أقدس بقاع الأرض عند المسلمين، فإليها أسري بالرسول

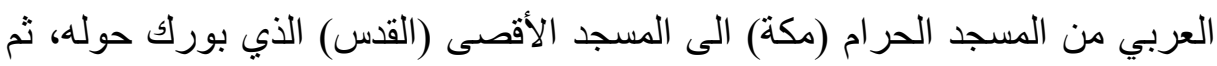

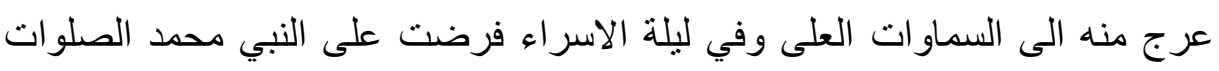
الخمس اليومية أول أركان الإسلام، فقد شيد الخليفة عمر مسجدا بالقرب من الصنة الصخرة

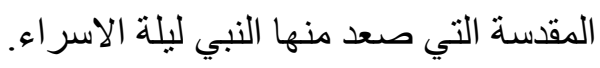

اتخذت المدينة منذ ذلك الحين طابعها الإسلامي واهتم بها الأمويون (661-

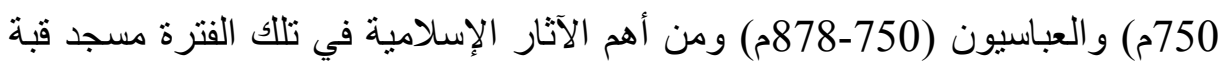
الصخرة Dôme du Rocher، الذي بناه عبد المالك بن مروان الإسل في في الفترة ما بين

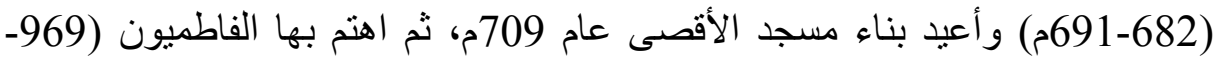

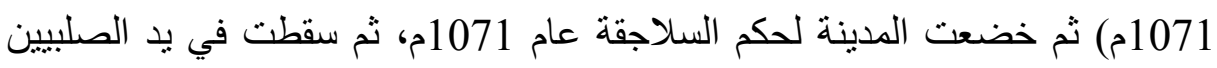

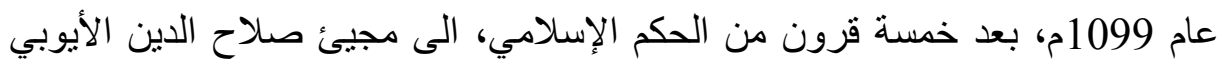

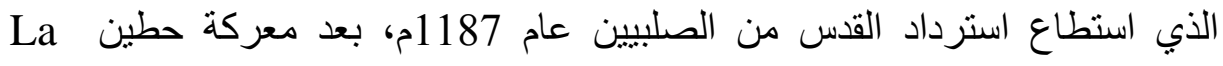
Bataille de Hattin

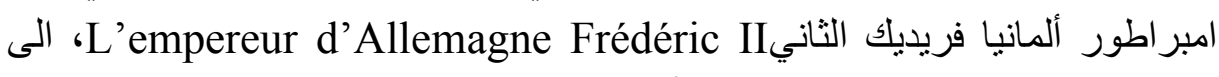
استردادها من طرف الملك نجم الدين أيوب عام 1244م، وضمت القدس الى المماليك الكي

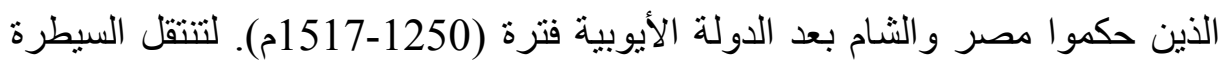
على فلسطين و على المدينة الى الدولة العثمانية التي ظلت تحت سيطرته التها طيلة أربعة 
قرون من الزمن (1517-1917) ـ أين كان يطلق على فلسطين اسم سوريا الجنوبية

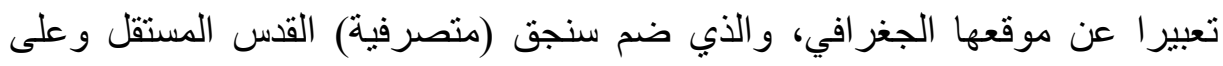

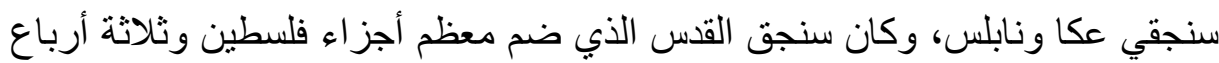

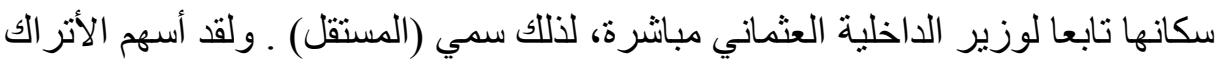

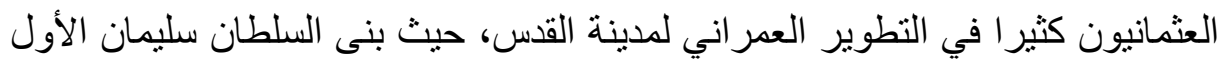

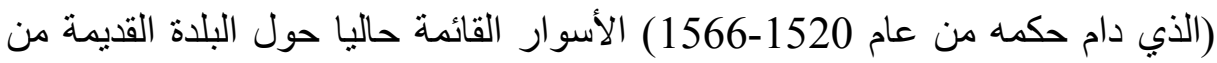

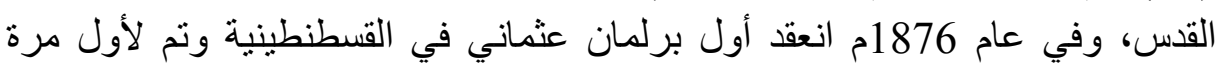
انتخاب نواب فلسطينيين فيه عن القدس، ووضع سنجق القد عام عام 1876 1874م تحت حكم القسطنطينية المباشر ، وقد بقي كذلك حتى وقوع فلسطين تحت الاحتلال البريطاني عام

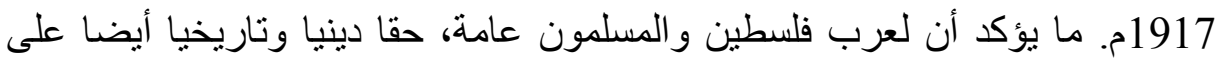

$$
\text { أولا: مفهوم الحق التاريخي في القانون التاريخي في القانون الدولي الدولي }
$$

يستخدم مصطلح اللقب أو الحق التاريخي Historic Titles or Rights،

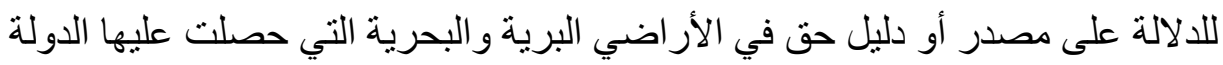
من خلال عملية التوطيد التاريخي، وقد نشأ هذا المفهوم في ممارسة الدول في في نهاية

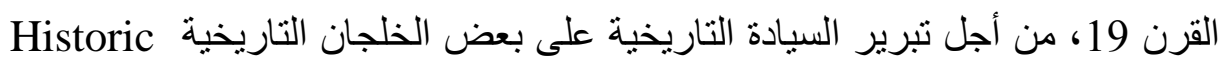

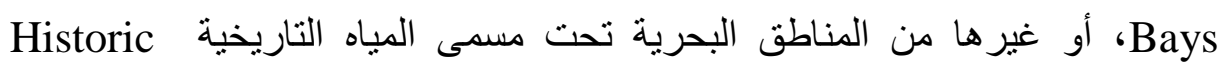
Waters الإقليمي للاول الساحلية المتجاورة. غير انه ظهر فير فيما بعد ميل في الأدبيات القانونية

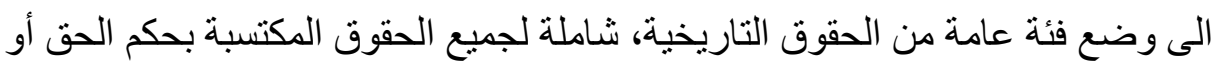

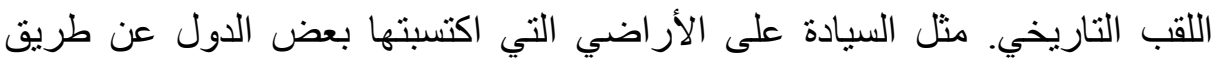

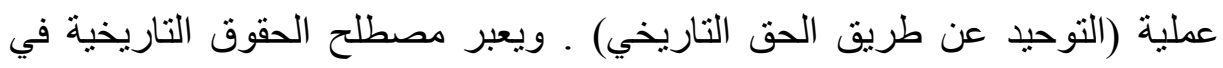

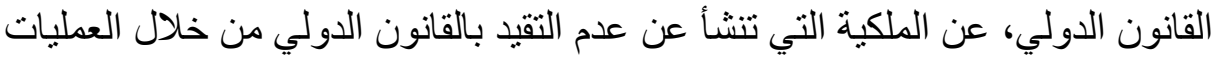

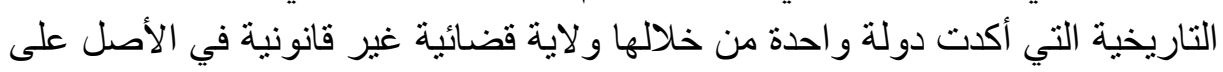

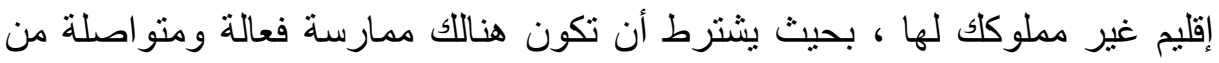

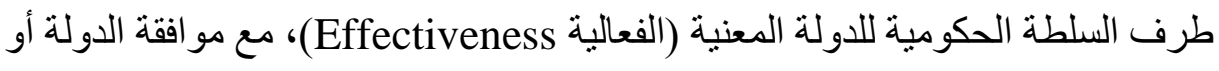

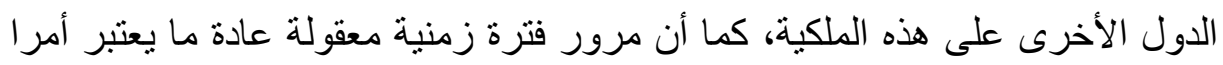
ضروريا لإنشاء مثل هذا الحق . هذه الأن

وفي هذا السياق نجد أن مفهوم الحق التاريخي في القانون الدولي يختلط بمفهوم

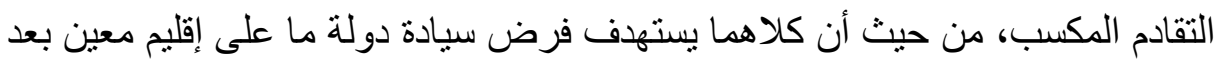

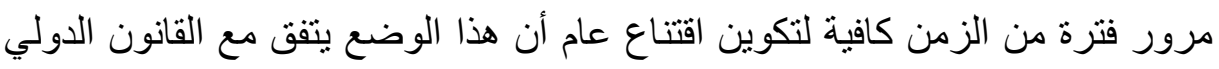

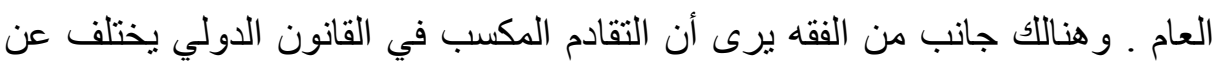
الحق التاريخي، ويبدو ذلك من استعر اض شروط التقادم المكسب التي تتحصر في : 
أن تقوم احدى الدول بوضع يدها ومباشرة حقوق السيادة على إقليم تابع لدولة

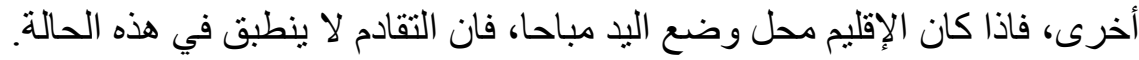

أن يكون وضع اليد هادئا بمعنى ألا يكون متناز عا عليه، أما إذا احتجت دولة

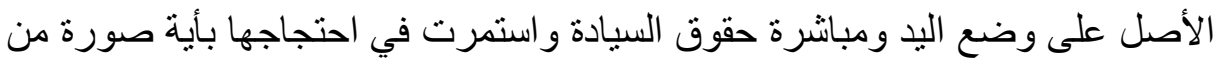
الصور فان شرط الهدوء لا ينوفر الئو

أن يكون وضع اليد لمدة طويلة، وليس هنالك معيار واضح يحدد طول المدة

اللازمة لكي يعد وضع اليد مستمرا.

وعليه فان اختلاف الحق التاريخي عن التقادم المكسب ينحصر فقط في عنصر

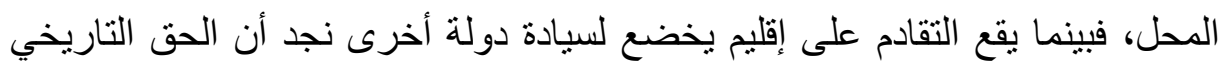

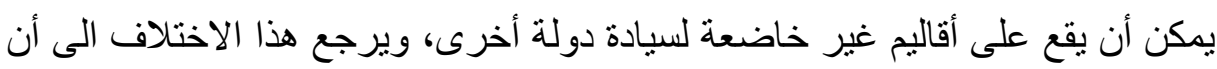

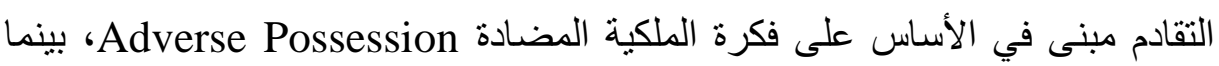
يرتكز الحق التاريخي على فكرة التدعيم المتواصل والتبييت التاريخي المتواصل Historical Consolidation

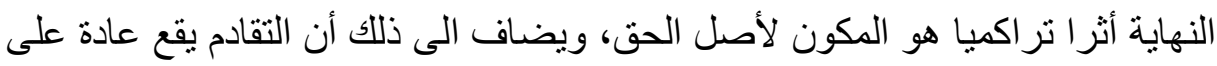

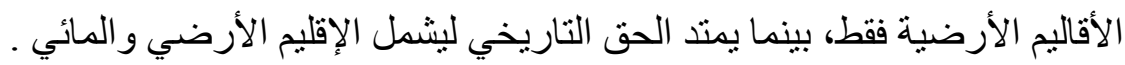
ثانيا: موقف القانون الدولي من المطالبات القانونية المستندة الى الحق التاريخي في القانون الدولي و العلاقات الدولية، لملكية الأراضي أهمية كبيرة لأن السيادة

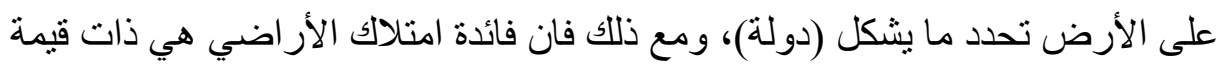

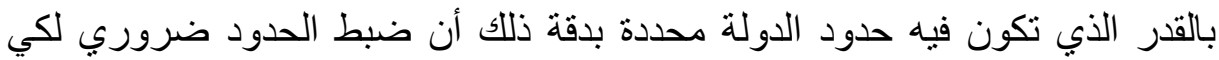
تعمل الدولة الحديثة، لذلك نجد أن الحدود تخضع لـود لمطالب إقليمية تنافسية بين الدول تتعدد فيها أوجه الادعاءات القانونية التي تبرر بها الدول الدئه ملكيتها للأر اضي أمام المحاكم

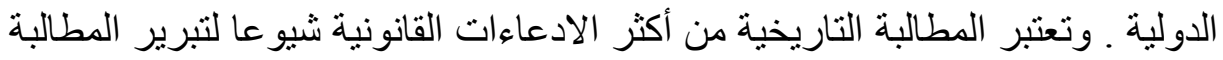

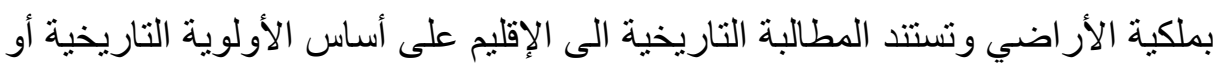

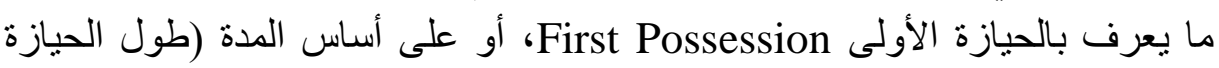

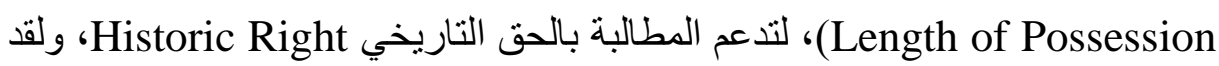
تمت مناقثنة مسألة المطالبة التاريخية في القانون الدولي كثير اً في السنوات المات الماضية.

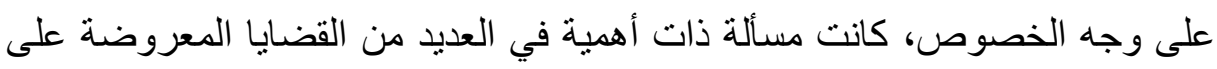

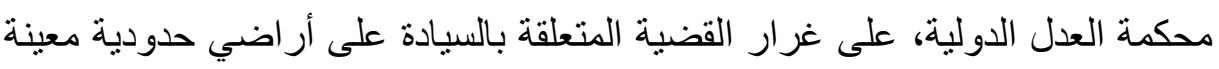

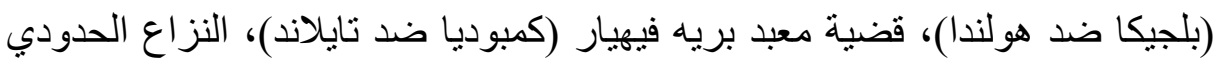

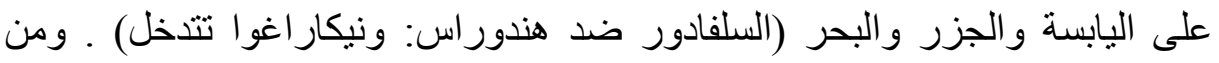

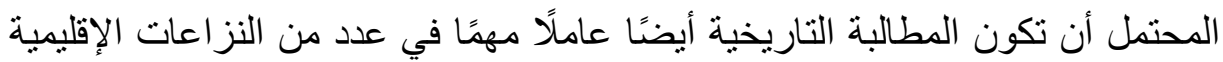
التي لم تعرض بعد على التحكيم أو التسوية القضائية. ما يهمنا هنا أنه بالبحث في موقف المحاكم الدولية من المطالبة بالإقليم على الجى

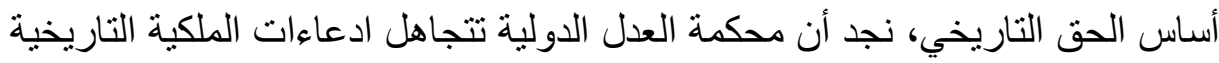

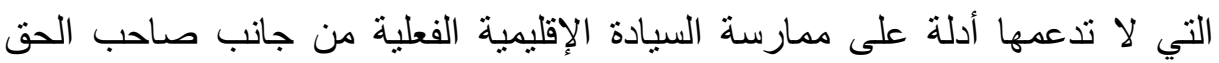


الأصلي، كما يتم تجاهل الخرائط القديمة (الأدلة التاريخية) التي ليست جزءا لا يتجزأ

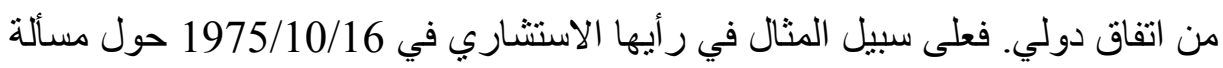

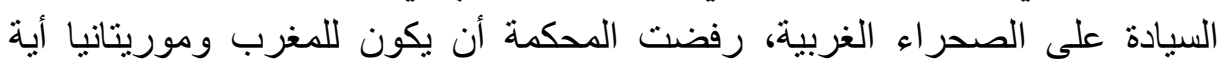

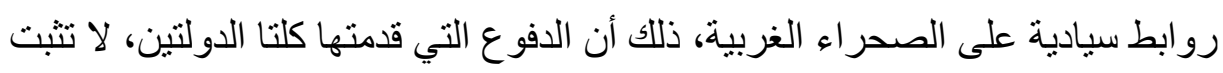

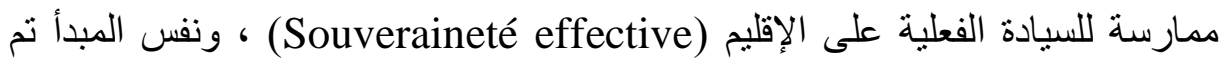

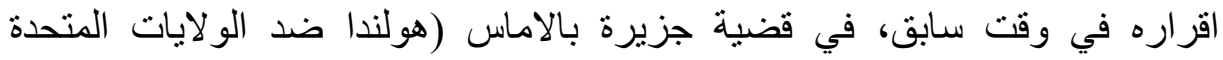

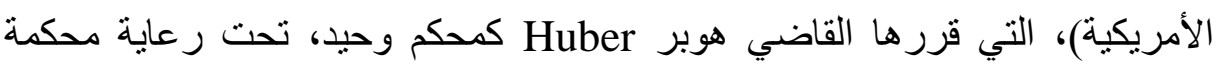

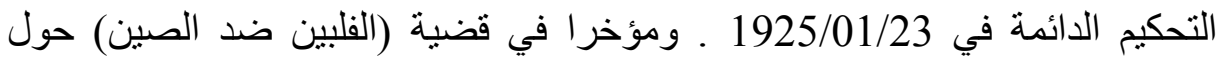

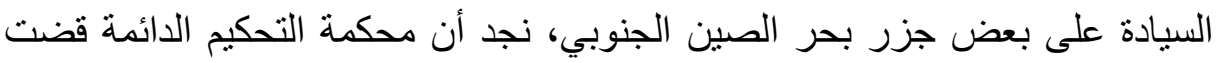

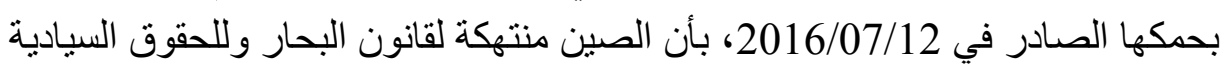

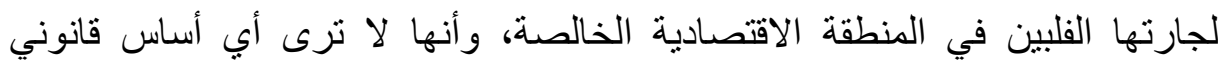

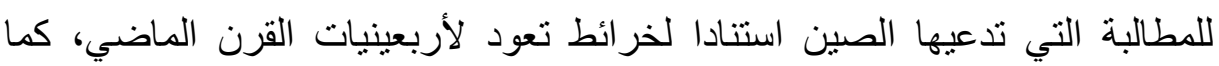
رفضت المحكمة حجة الصين بأنها تتمتع بحقوق ناريخية على معظم بحر الصين

الجنوبي.

كما أنه تاريخيا، موجات التحرر التي شهدها العالم في القرن العشرين دفعت بالقانون الدولي لإقفال الباب أمام المطالبات التاريخية بالإقليم باعتماده مبدأ (قدسية

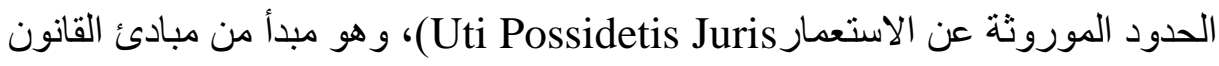
الدولي العرفي الذي يعمل على الحفاظ على حدود المستعمر ات الناشئة كدول. تم تطبيقه

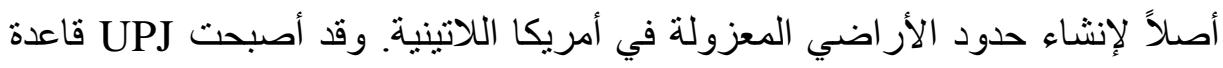

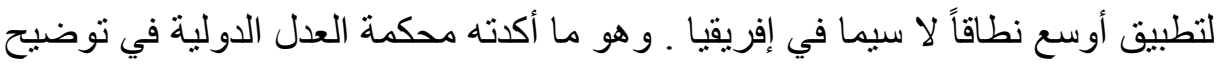

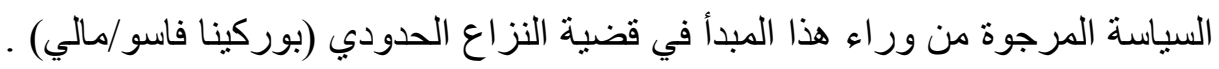

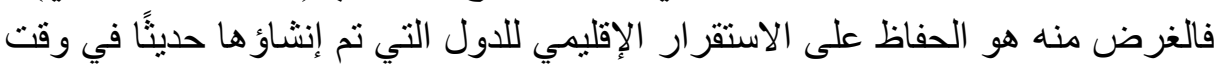

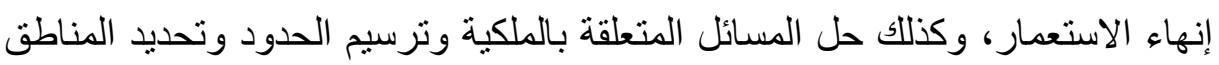

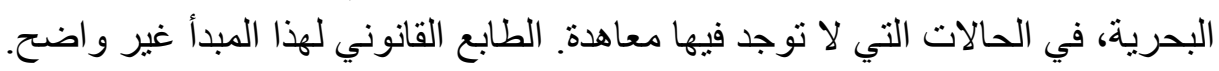

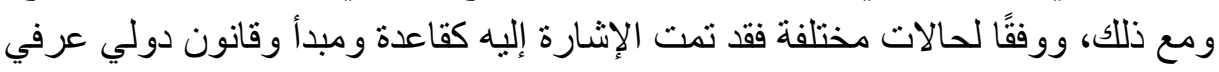
و عقيدة سياسية . وماك.

\section{المطلب الثاني: مدينة القدس في القانون الدولي}

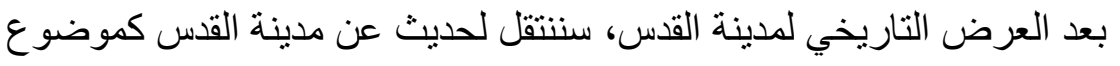

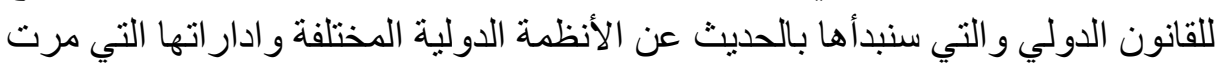
على مدينة القدس عبر تاريخها الحديث وهذا عمليا منذ سقوط ولاية الدولة العثمانية

الفرع الأول: الإدارة الدولية لمدينة القدس

أولا: القدس في اتفاق ساكس-بيكو

في ماي 1916م تم التوصل إلى اتفاق سايكس بيكو بين الحكومتين البريطانية 
و الفرنسية، من أجل تقسيم المقاطعات العربية للإمبر اطورية العثمانية في ذروة الحرب العالمية الأولى، حيث تم تقسيم هاته الأخيرة الى خمسة مناطق:

منطقة حمراء: تضم تقريبا العراق بحدوده الحالية وتخضع للسيطرة الادارية البريطانية المباشرة. منطقة زرقاء: تضم سوريا ولبنان وشمال فلسطين تخضع الى الى الى الى

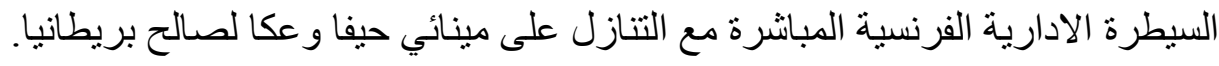
منطقة سمر اء: تضم القس وباقي أجزاء فلسطين، تخضع للإدارة الدولية. مع منطقتين

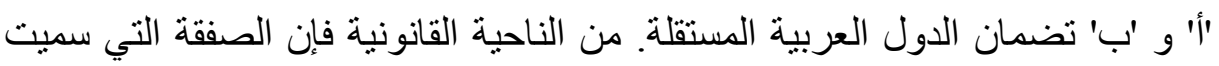

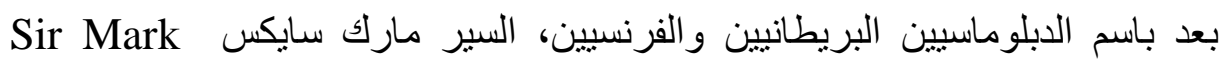

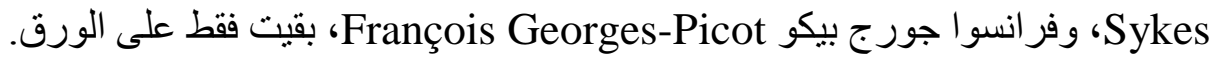
الا أن أهميتها تكمن في كونها البادرة الأولى التي بموجبها تم اخضاع مدينة

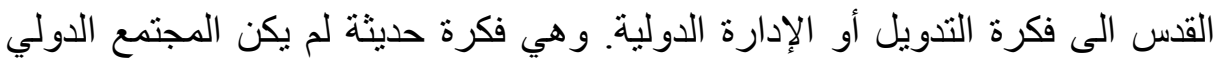

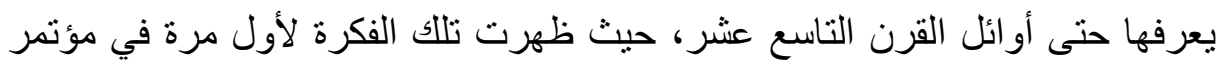

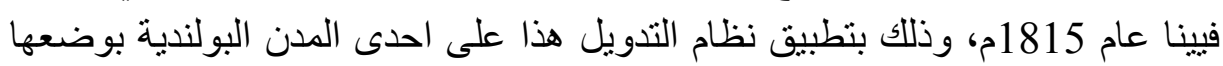

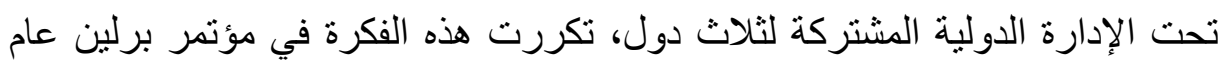

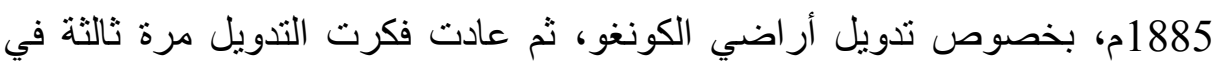

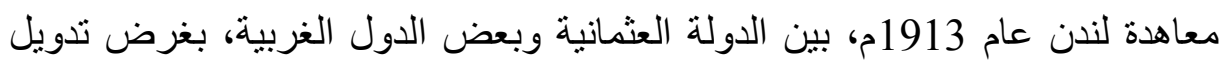

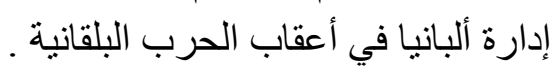

\section{ثانيا: القدس في صك الانتاب البريطاني}

الانتداب نظام أقيم في أعقاب الحرب العالمية الأولى، وقد جاء النص عليه في

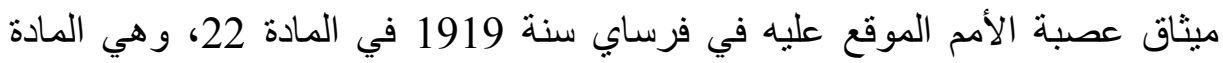

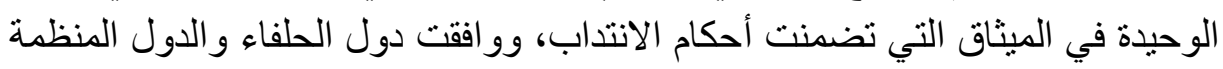

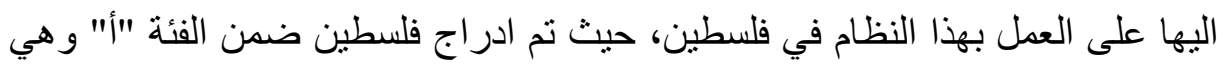

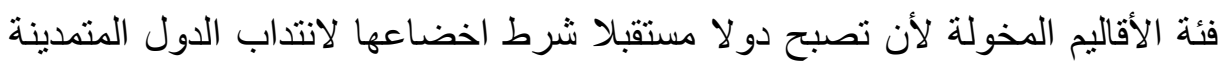

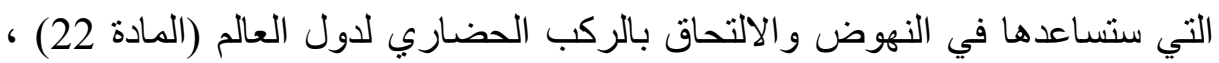

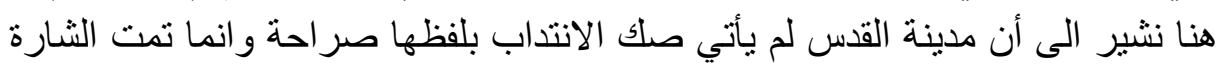

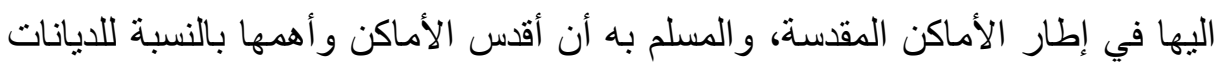

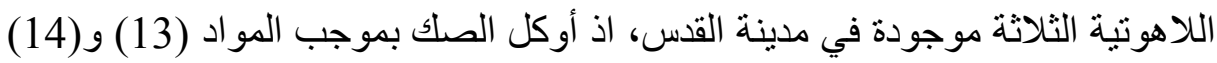
و(15) والتي جاءت بصيغة آمرة، الى بريطانيا مهمة تسيير هاته الأماكن إداريا

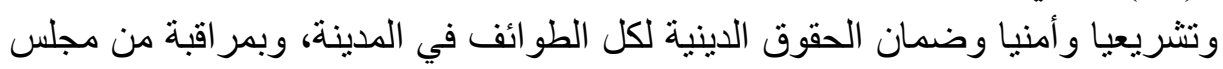

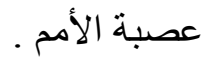

The وفيما يتعلق بموقع ديني له أهمية خاصة في القد، حائط المبكى Wailing Wall

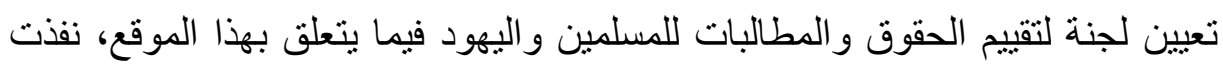
الحكومة البريطانية هذا التحقيق، ونتيجة لذلك، قدمت تشريع (نظام حائط المبكى)

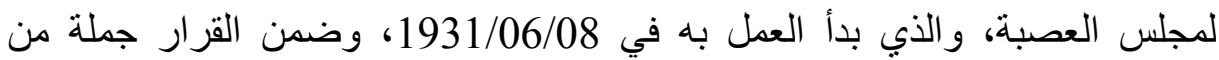


الحقوق و الو اجبات والإجر اءات التي تفعل حرية العبادة بالمكان.

وفي ذات السياق فان أعلى سلطة قضائية في القانون الدولي ألا وهي محكمة

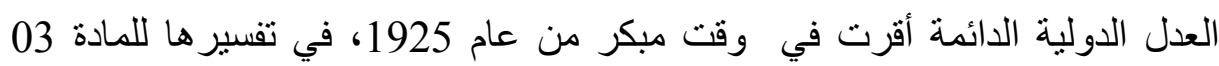

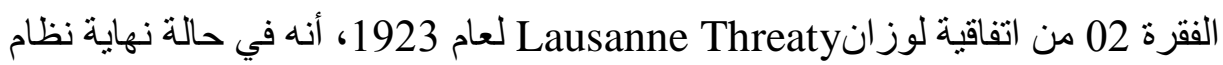
الانتداب، يجب على مجلس عصبة الأمم اتخاذ كل الترتيبات اللازمة للحماية الأبدية

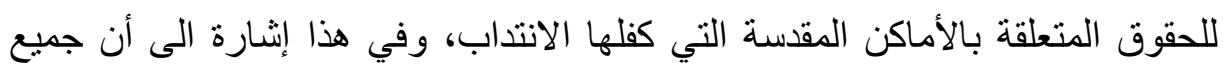
الالتز امات و الحقوق القانونية المتعلقة بالأماكن الدينية المقدسة التي كفلتها عصبة الأنة الأمم

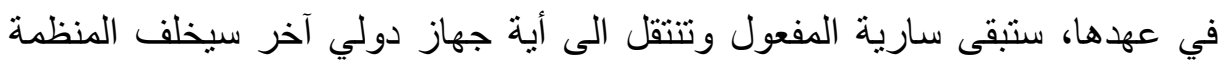

ثالثا: القدس في قرار التقسيم 181

ان الصعوبات التي ستندلع في ظل الانتداب البريطاني، و الصدامات التي ستمس القس أولاً في عام 1920، ثم مرة أخرى في 1928-1929، ستؤدي إلى فكرة الجسد الهن المنفصل Corpus Separatum، المقترح للقد في خطة تقسيم فلسطين للأمم المتحدة بالقرار 181 في 1947/11/29 للجمعية العامة ــ ـوهو في في الحقيقة تبني

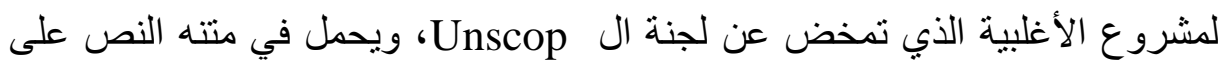

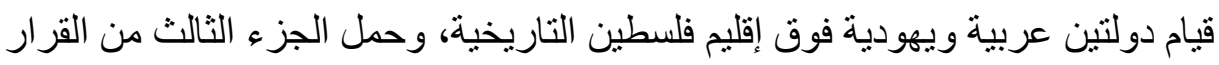

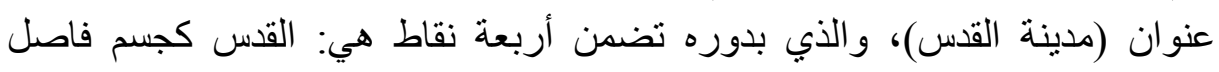

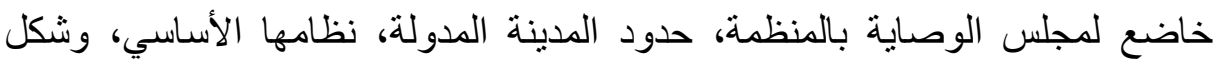

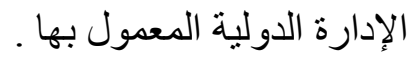

لقد حاولت الأمم المتحدة بقرار التقسيم 181 أن تطبق نفس نظم التدويل الكامل

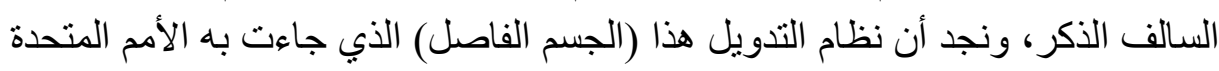

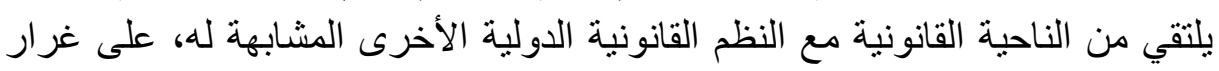

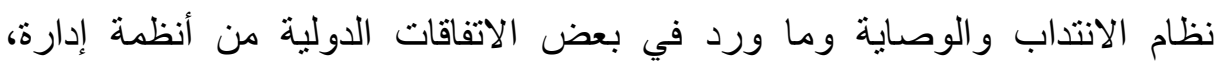

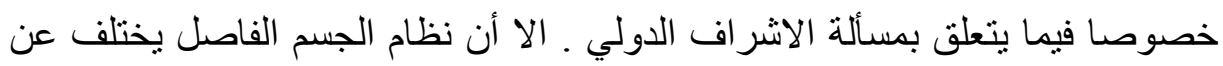

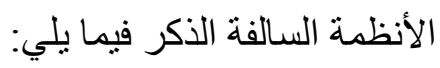

أن السلطة التي تقوم بالإشر اف و الإدارة، هي ليست مجموع دواتين أو أكثر و لا

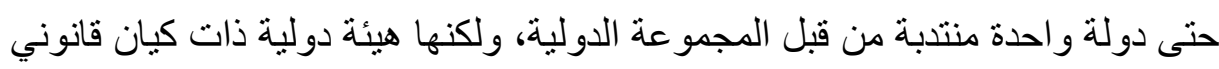

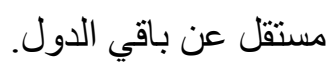

يختلف في أغر اضه من حيث أنه فكرة لا تهدف الى الاستقلال وتقرير المصير

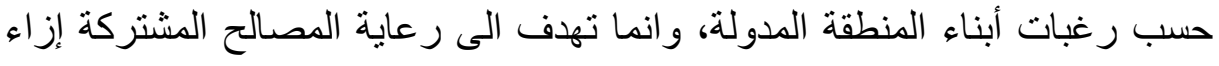

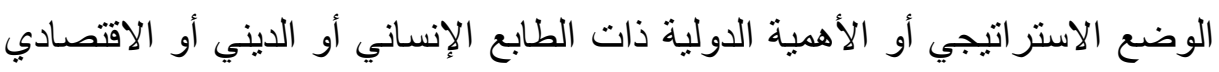
للمنطقة.

يكمن أساسه القانوني في نظامه الاتفاقي المتعدد الأطر اف، والمفتوح لانضمام جميع أعضاء الأسرة الدولية ذات المصالح المشتركة، وهو في ذلانك يختلف عن الأنظمة الأفي 
الأخرى التي أساسها الاتفاق الثنائي أو الجماعي المحدود الأطر اف.

لا يعني نظام التدويل هنا تدعيم سيادة دولة ما استعمارية، كما هو الثأن في نظام

الانتداب مثلا، و انما يمارس حقوق السيادة فيه شخص دولي جديد ذو إرادة مستقلة

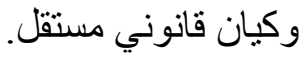

الفرع الثاني: القدس عاصمة للاولتين

لقد أدت المتغيرات التاريخية وسياسة فرض الأمر الواقع بالقوة الى افثال نظام الإدارة الدولية على مدينة القدس، فوفقا للأحداث التي سنأتي على ذكر ها سوف يته يتم تبني

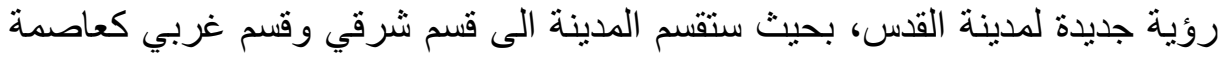
للدولة العربية و اليهودية على الترنيب.

\section{أولا: الاحتلال العسكري للمدينة}

عقب صدور القرار 181، وإعلان بريطانيا سحب قو اتها من فلسطين وبذللك التهي

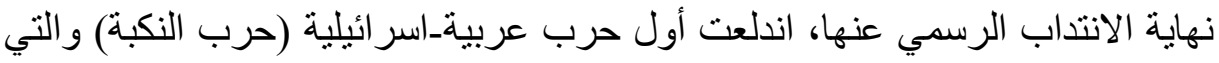
نتج عنها، هزيمة للجيوش العربية السبعة واستلاء القوات الصهيونية على نحو الصو من أرض فلسطين وتهجير حوالي 57\% من الثعب الفلسطيني من أرضهم (لاجئي

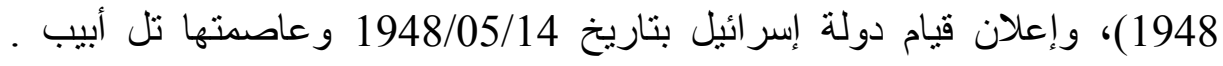

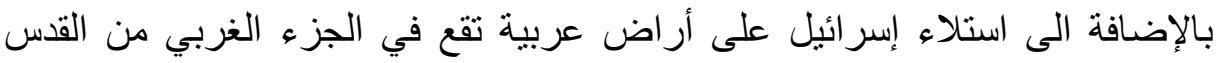

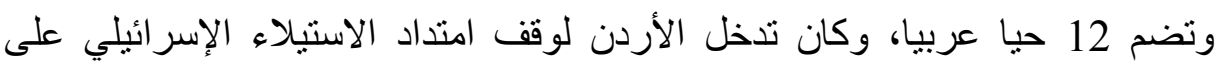

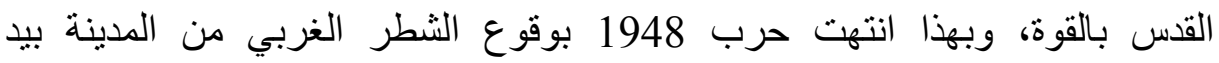
الاسر ائيليين و الجزء الثرقي بيد الأردنيين ـ وقد أصدرت الجمعية العامة قرار ها رقم

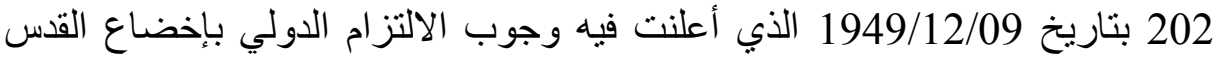

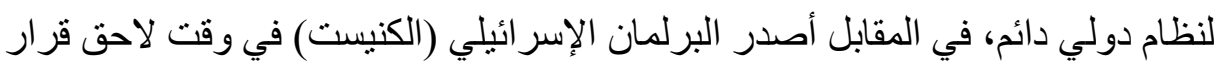
بتاريخ 1950/01/12 ينص على نقل مقر الحكومة الإسر ائيلية من تل أبيب الى مدينة

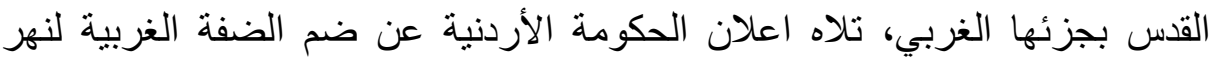

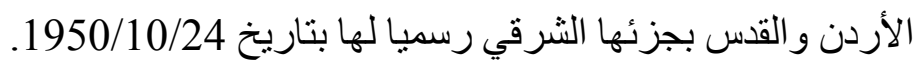

بنشوب ثاني حرب عربية-إسرائيلية، من 05 الى 10 جوان 1967، الاند إنل مجلس الامن الدولي ودعا الى وقف اطلاق النار، وقد استجاب أطر اف النزاع اع بعد ستة

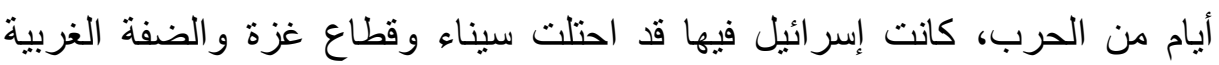
و القدس الثرقية وجزء من مرتفعات الجو لان، أصدر بعدها مجلس الأمن الدولي بتاريخ

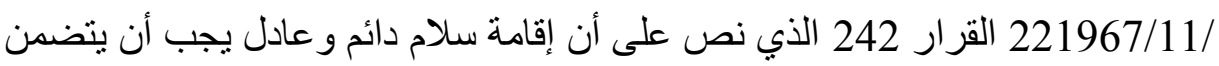

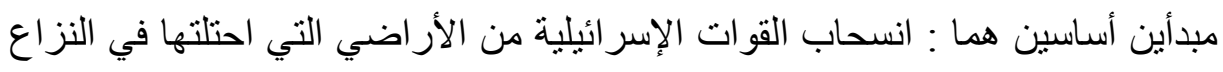

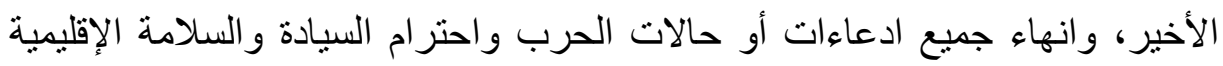

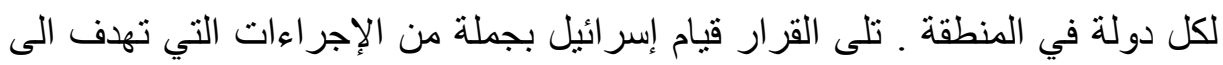

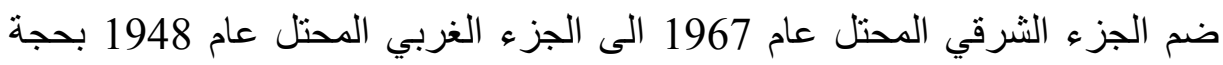
(توحيد المدينة)، فقد قام الكنيست بتاريخ 1967/06/27 بإجراء تعديلا لقانون أنظمة السلطة والقضاء لسنة 1948، كما قام بتعديل آخر على قانون البلديات الإسر ائيلي وهو 
القانون رقم 06 لسنة 1967، و الذي نص على الغاء سريان القوانين الأردنية على

وفي رد الجمعية العامة على تشريعات الحكومة الإسر ائيلية المتعلقة بالقدس،

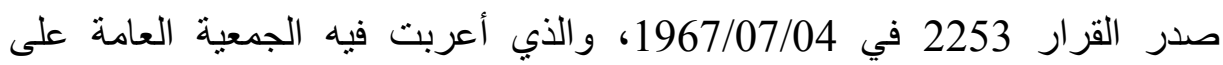

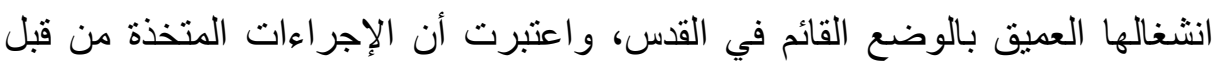

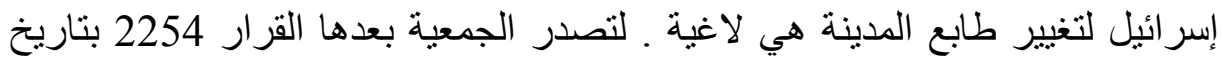

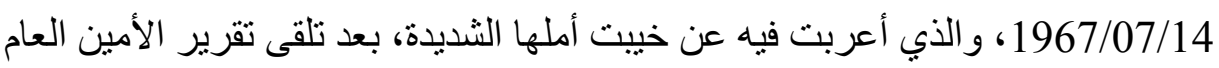

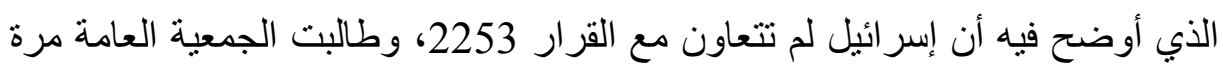

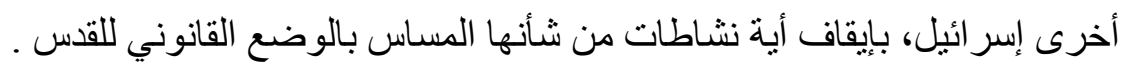

\section{ثانيا: الاعتر اف الدولي بالقدس عاصمة للاولتين}

في عام 1980، أقرت الكنيست قانون أساس، بناء عليه فإن القدس الموحدة

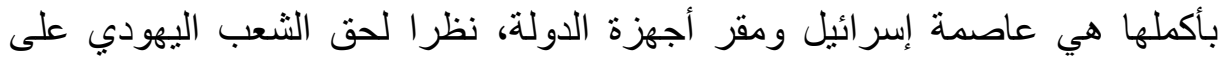
المدينة. من وجهة نظر القانون الدولي، لا تمتلك إسرائيل أي شيء سواء فئلفي في الجانب

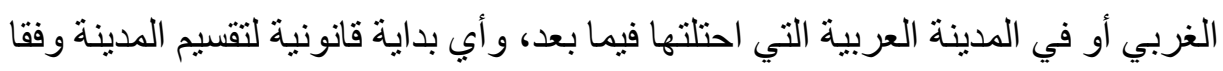

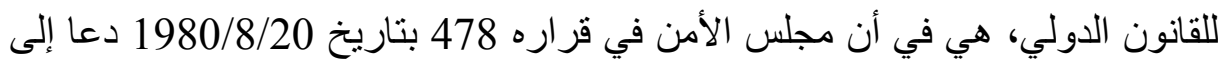

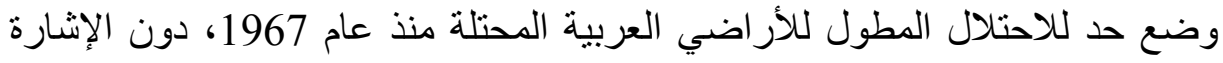
صر احة إلى تلك المحتلة منذ عام 1948. ويؤكد نفس القرار على أن (الاستيلاء على لإنى

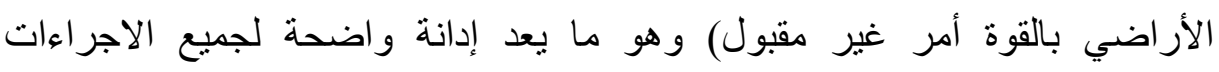

الإسر ائيلية.

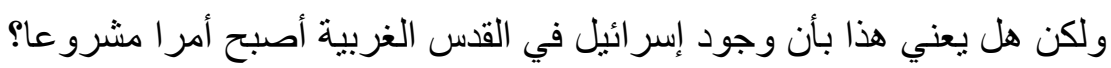

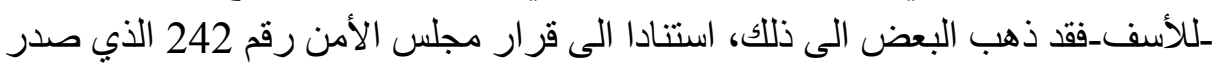

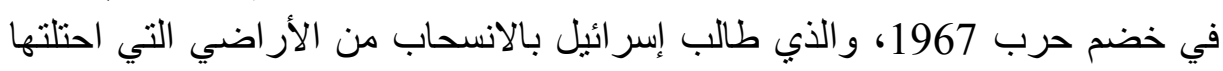

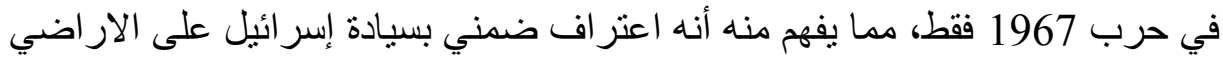

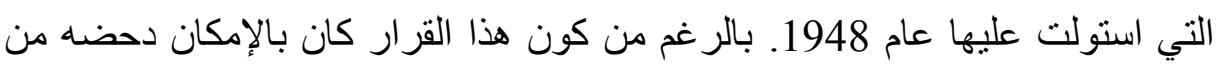

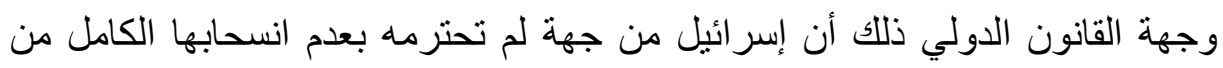

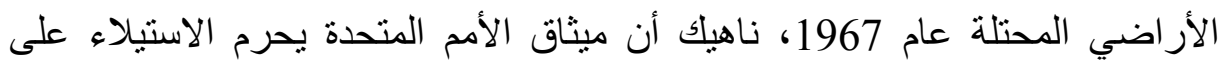

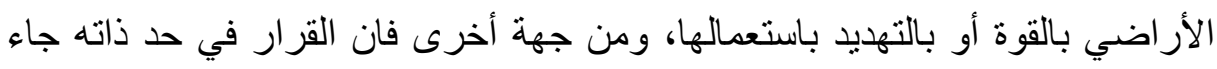

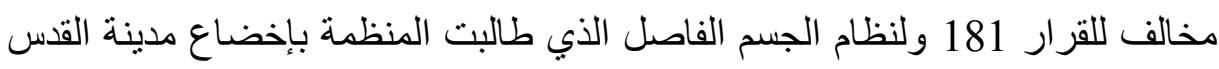

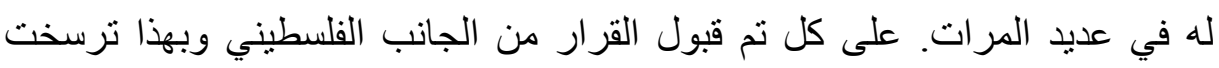
الفكرة على الصعيد الدولي و الصعيد الداخلي الفلسطيني في قيام دولة فلسطينية عربية على حدود 1967 و عاصمتها القدس الثرقية.

ففي اعلان قيام الدولة الفلسطينية في 15 نوفمبر 1988 بالجزائر، أعلنت منظمة

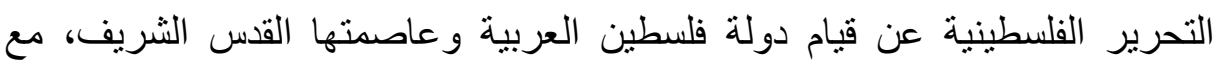

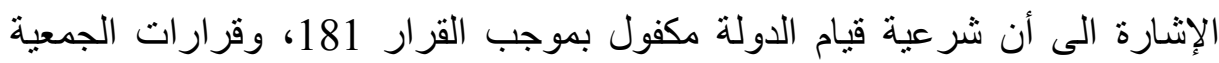


العامة للأمم المتحدة التي رسخت حقوق الثعب الفلسطيني الغير القابلة للتصرف. هنا

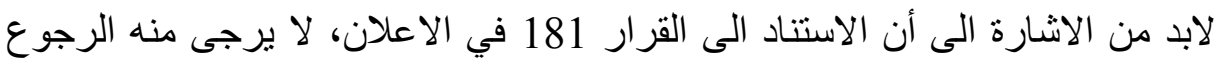

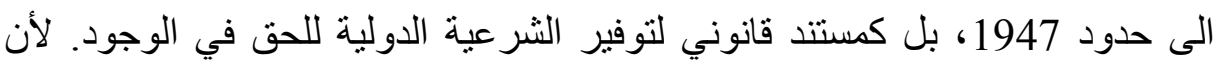

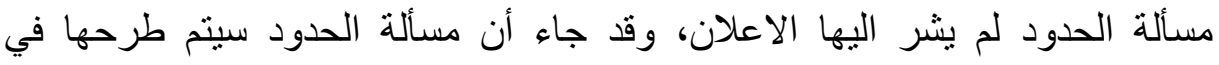
مفاوضات لاحقة.

في عام 1993، أدت مفوضات السلام المباشرة بين منظمة التحرير وحكومة إسر ائيل، عقب مؤتمر السلام بمدريد الى اصدار اتفاق سلام أولي (اتفاق أوسلو)، و هو

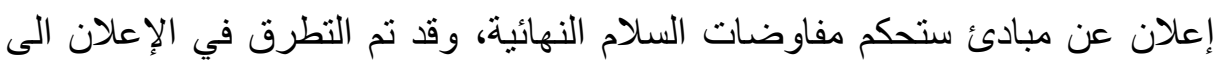

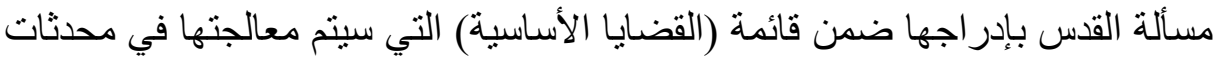

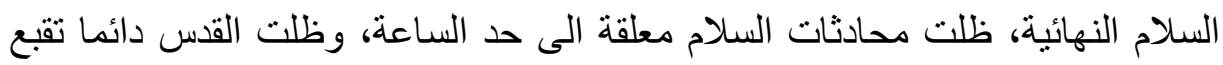

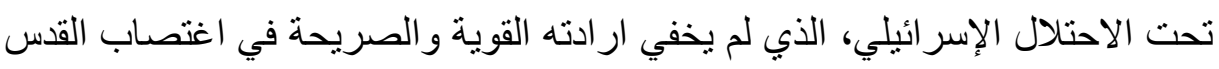
ككل وجعلها عاصمة أبدية لإسر ائيل. بدعم طبعا من الولايات المتحدة الأمريكية فقد الإئه

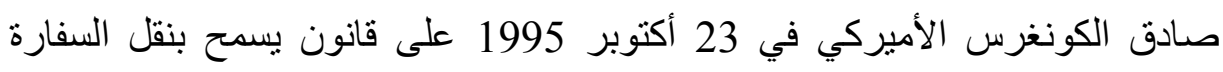

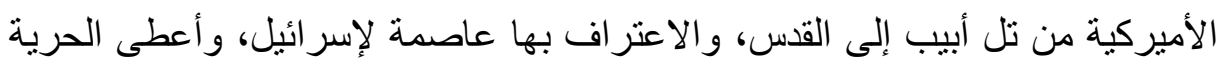

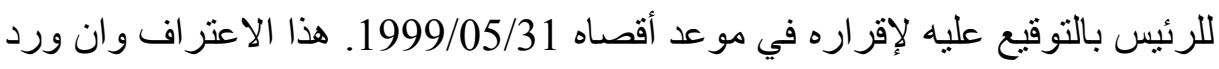

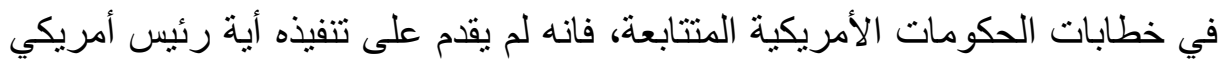

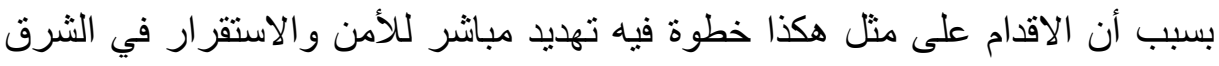

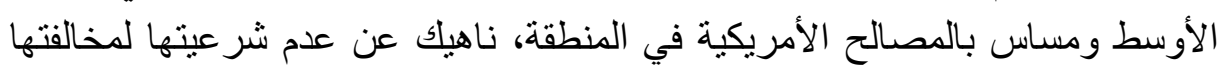

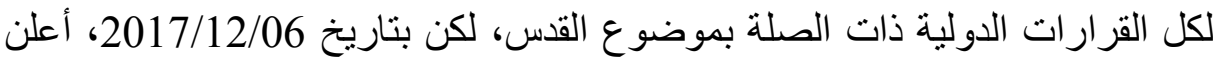

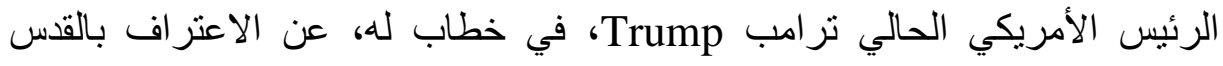

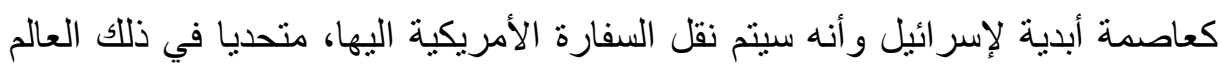

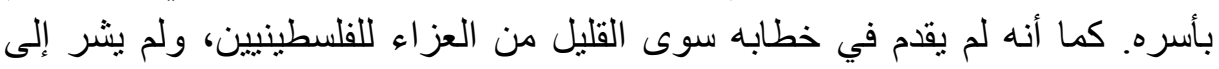

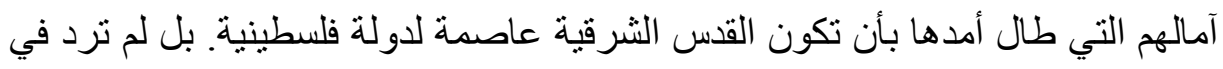

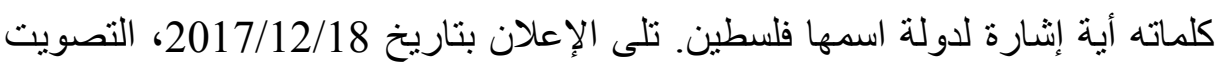

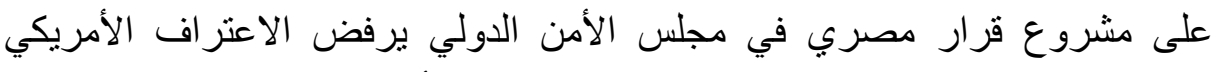

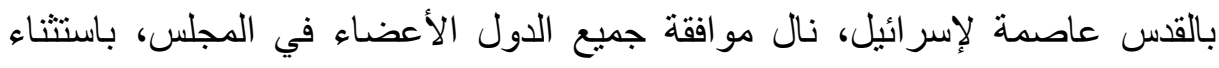

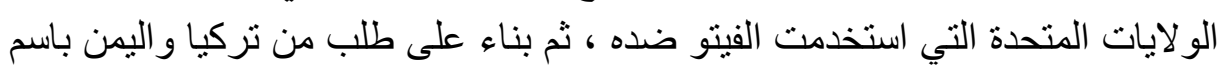

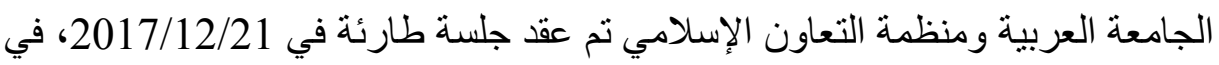

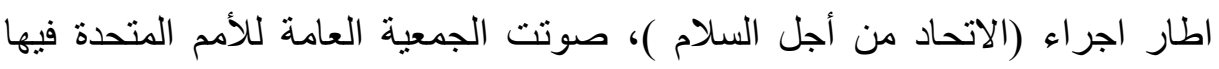
بأغلبية 128 صوتا لصالح القرار رقم(A/ES-10/L.22)، الذي يطالب الجميع بعدم

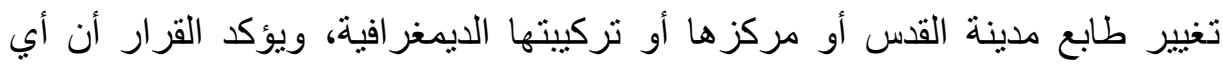

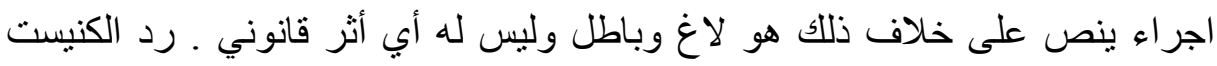

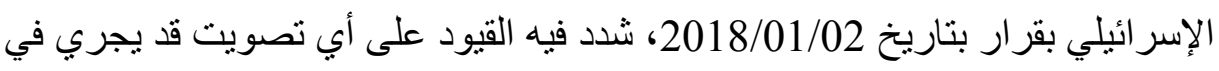

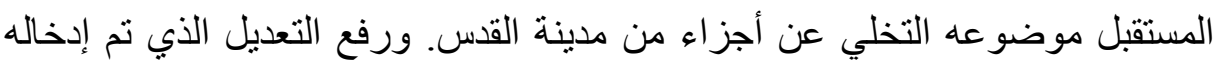

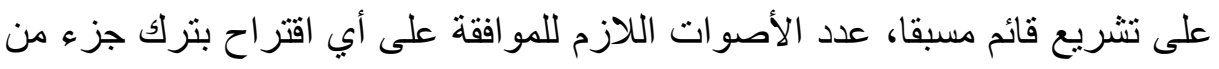

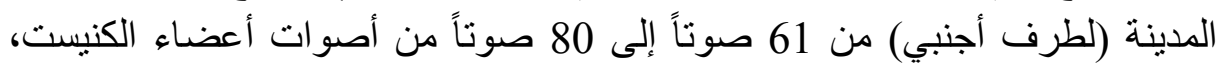
المؤلف من 120 عضواً، أي ثلثي عدد الأعضاء، و هي أغلبية شبه مستحيلة. 
وفي آخر خطوة أقر الكنيست الإسر ائبلي بتاريخ 2018/07/19، في قراءة ثالثة

وأخيرة لمشروع قانون أساس تحت مسمى (قانون الدولة القومية)، بأغلبية 62 نائبا

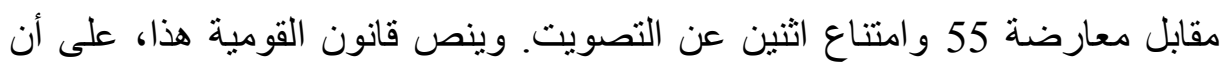

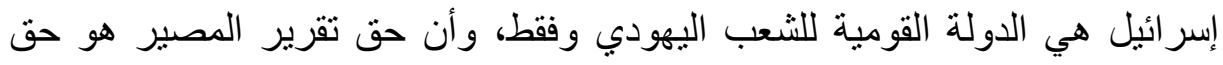

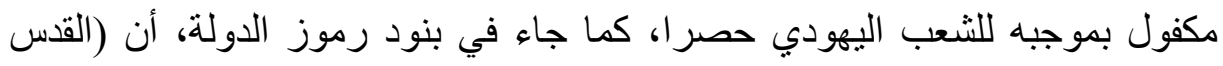

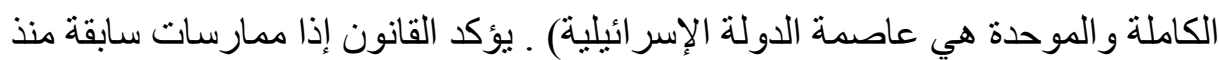

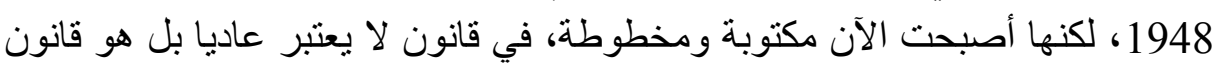

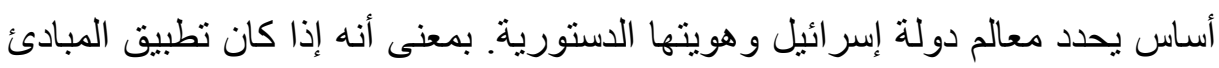

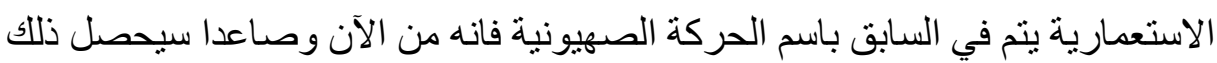
باسم سلطة القانون.

\section{الخاتـــة:}

لقد عمدت إسرائيل منذ قيامها بالاستيلاء على القد، ضمن سعيها للسبطرة

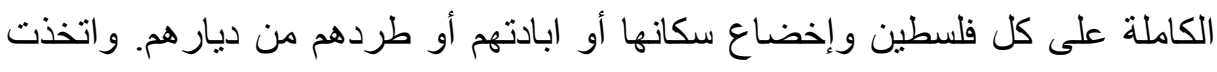

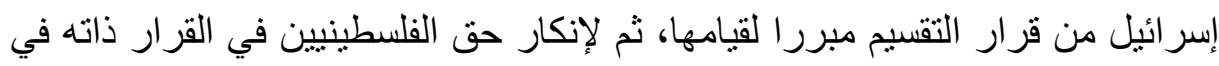

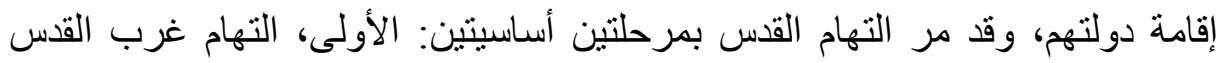
سنتي 1949-1950 و الثانية، التهام شرق القد منذ سنة 1967 وضمهام رسما رسميا و اعلانها عاصمة أبدية لإسر ائيل سنة 1980. 1980. ووصلت هذه الدائرة قمة مأساتها بإعلان

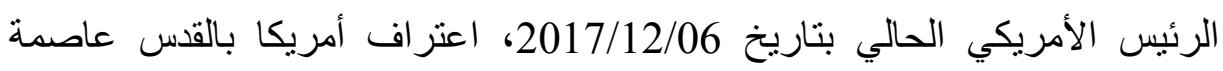

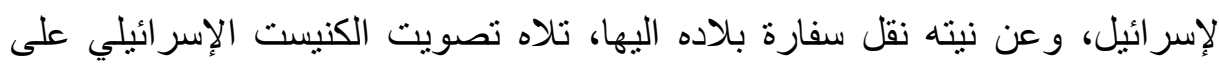

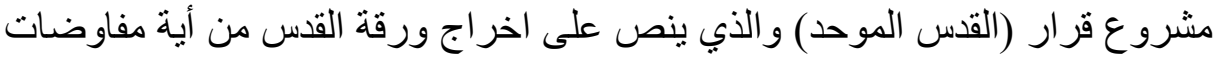

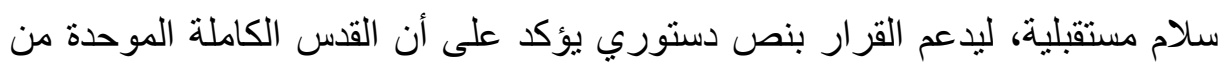

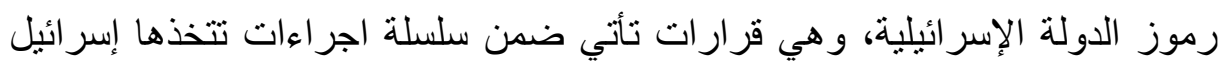
بهدف تعزيز واقع القدس وفقا للرؤية المستقبلية التي يقوم عليها الاحتلال بجعل المدينة عاصمة أبدية للدولة اليهودية. و هكذا يتضح أن مدينة القد قد القئ انتقلت من مرحلة التبعية

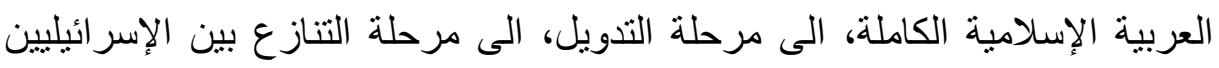

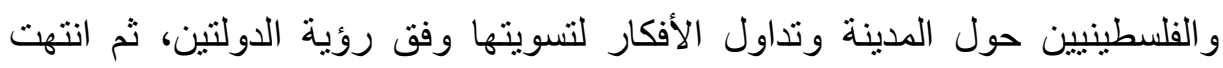
بالإعلان عن تبعية المدينة بأكملها لإسر ائيل. ضاربة بـانة بعرض الحائط جملة من القو انين

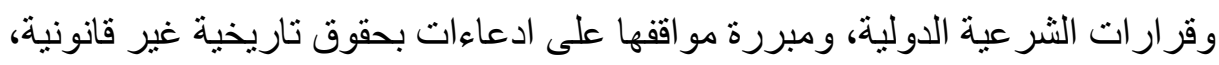

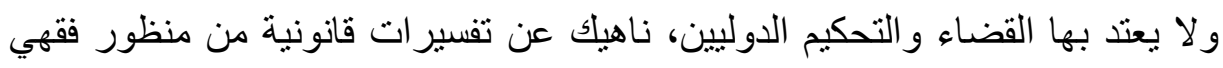
أحادي الجانب، مدعم بسياسة فرض الو الو اقع بالقوة العسكرية.

\section{النتائج والتوصيات:}

ان الادعاء الإسر ائيلي بأن لها حقا تاريخيا على فلسطين عامة و القدس بالأخص،

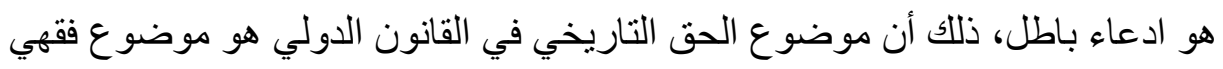

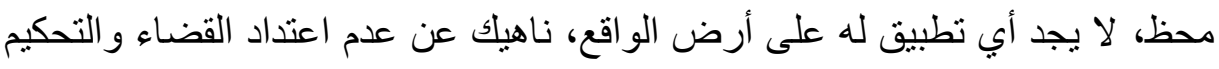

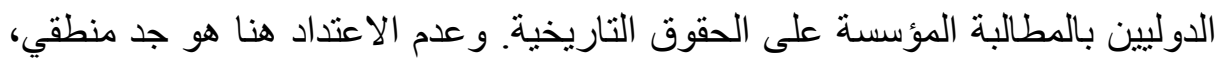


ـماهي الثورات التي قد تحدث في العالم إذا كان من المقرر أن تتعطل ساعة التاريخ

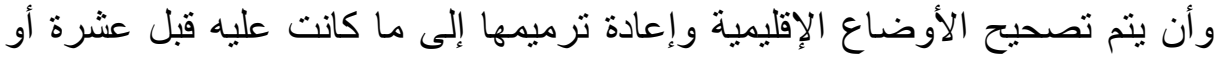

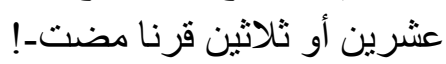

بالنظر الى الطابع الديني والانساني العالمي لمدينة القدس، وبالنظر الى خطر التهويد الذي تو اجهه، يمكن إعادة النظر في مسألة اخضاعها الى نظام إدارة دولية من التهالئ جديد، على جزئها الشرقي على الأقل، الى غاية تحقق حل الدولتين، خاصة و أنه ممكن من الناحية القانونية، لاختلاف نظام الإدارة الدولية أو الجسم الفاصل، عن عن الإلى نظام الوصاية الذي تم انهاء العمل به سنة 1994.

بما أن موضوع القدس كان من الموضوعات الأساسية التي من المفترض أن

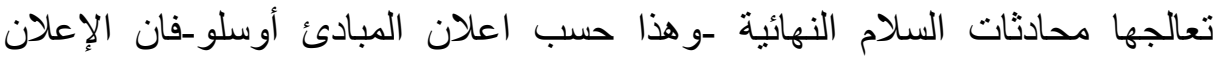

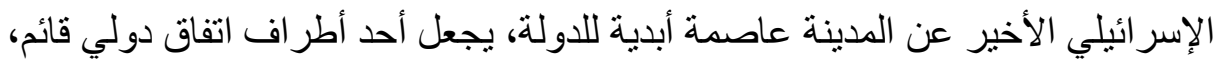
قام بإخلال جسيم ببنود هذا الاتفاق، ما بستلزم سقوط الاتفاق من الناحية القانونية. (نهاية

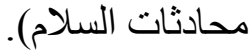

الإجراءات التي اتخذتها إسر ائيل لامج القدس الغربية في إسرائيل و التي اتخذتها

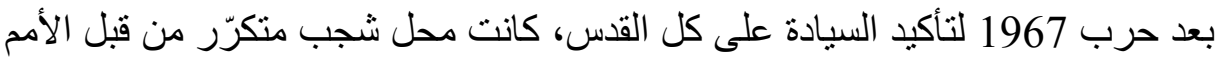
المتحدة، وليس لها أبي أثر قانوني.

يعرف تاريخ مدينة القس الآن رابع محاولة لتهويد المدينة وجعلها عاصمة

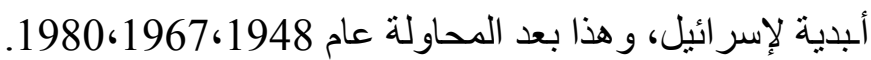

ان اعلان القس الموحدة عاصمة لدولة الاحتلال، هو استثناء و لا يمكن القياس

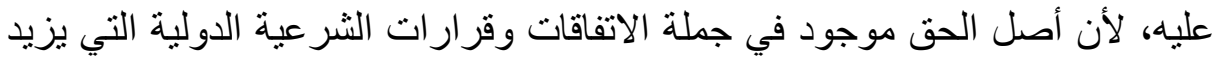

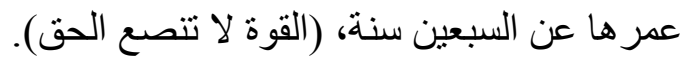

لا وجود لدولة فلسطينية، من دون القدس -بشقها الشرقي على الأقل-عاصمة

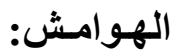

1. http://alqudsgateway.ps/wp/?p=221 20:54 2018/01/08

2. https://www.lesclesdumoyenorient.com/A-relire-en-lien-avec-1actualite-Jerusalem-une-ville-divisee-chargee-de.html 2018/01/08 21:04

3. محسن محمد صالح، القضية الفلسطينية: خلفياتها التاريخية وتطوراتها المعاصرة، مركز

الزيتونة للدراسات والاستشارات، بيروت، لبنان، طبعة مزيدة ومنقحة، 2012، ص ص 21.

4.

5. Omar Massalha, Israël et Palestine : deux émanations inachevées de l'occident ?, édition publisud, France, 2006, p 23.

6. Op, Cit, p 24.

7. Omar Massalha, Op, Cit, p 25. 
8. يث انفصلت المملكة العبرية الواسعة لملوك داوود وسليمان سبعد وفاة هذا الأخير

$$
\text { حوالي } 930 \text { ق.م -الى مملكة إسرائيل ومملكة يهوذا. }
$$

9. David André Belhassen, Gérard Nissim Amzallag, La haine maintenant ? Sionisme et palestinisme : les sept pièges du conflit, édition la différence, France, 2006, p 21 et 22.

10. Ibid.

11. https://www.breakingisraelnews.com/99002/trumps-jerusalemdeclaration-next-step-third-temple/\#/ 12:32 2018/02/05

12. http://mfa.gov.il/MFAAR/InformationaboutIsrael/Jerusalem/Pages/ jerusalem-\%20the\%20holy\%20city.aspx 14:18 2018/01/13

$$
\begin{aligned}
& \text { 13. حسن الباش، القدس من الاسراء الى وعد الآخرة: سبع آيات تختزل التاريخ، دار قتيبة }
\end{aligned}
$$

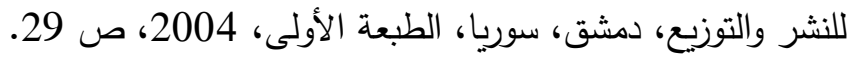

$$
\begin{aligned}
& \text { 14. المرجع السابق، ص } 15
\end{aligned}
$$

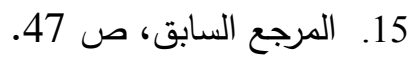

$$
\begin{aligned}
& \text { 16. محمد محسن عادل، مرجع سابق، ص-ص الص 13و 14. }
\end{aligned}
$$

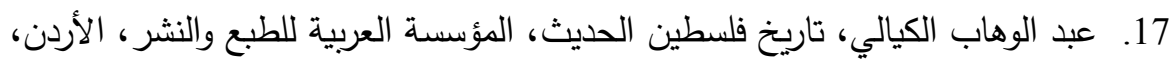

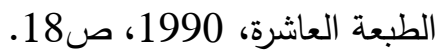

$$
\begin{aligned}
& \text { 18. سورة الاسراء الآيات 01-07، القرآن الكريم. } \\
& \text { 19. عبد الوهاب الكيالي، مرجع سابق، ص الابات } 18 . \\
& \text { 20. المرجع السابق، ص } 19 .
\end{aligned}
$$

21. http://www.etudes-francaises.net/jerusalem/histoire.htm

14:11 2018/02/05

$$
\text { 22. عبد الوهاب الكيالي، مرجع سابق، ص } 37 .
$$

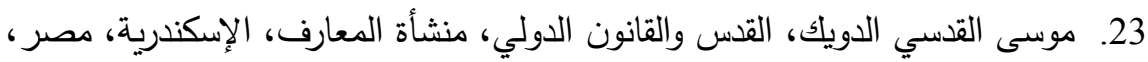

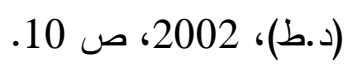

24. Andrea Gioia, Historic Titles, Oxford Public International Law, Available at :

http://opil.ouplaw.com/view/10.1093/law:epil/9780199231690/law9780199231690-e705 29/01/2018 13:05

25. http://www.oxfordreference.com/view/10.1093/oi/authority.201108 03095938831 28/01/2018 14:40

26. Andrea Gioia, Op Cit.

$$
\begin{aligned}
& \text { 27. محمد إسماعيل علي السيد، مدى مشروعية أسانيد السيادة الإسرائيلية في فلسطين، عالم } \\
& \text { الكتب للنشر والتوزيع، القاهرة، مصر ، (د.ط)، 1975، ص } 44 . \\
& \text { 28. ذات المرجع السابق. } \\
& \text { 29. المرجع سابق، ص } 45 .
\end{aligned}
$$


30. Brian Tylor Summer, TERRITORIAL DISPUTES AT THE INTERNATIONAL COURT OF JUSTICE : https://pdfs.semanticscholar.org/c0d2/8f2e24a9ac497b512d67c7a4 8f8434fea87e.pdf 29/01/2018 11:31

31. Ibid.

32. Rafaa Ben Achour, INSTITUTIONS DE LA SOCIETE INTERNATIONALE, Centre de Publication Universitaire, Tunisie, 3éme Edition, 2003, pp 95et96.

33. Ibid.

34. https://www.nytimes.com/2016/07/13/world/asia/south-china-seahague-ruling-philippines.html 12:55 19/05/2018

35. https://www.law.cornell.edu/wex/uti_possidetis_juris 05/07/2018 $16: 38$

36. [UPJ is a] general principle, which is logically connected with the phenomenon of the obtaining of independence, wherever it occurs. It's obvious purpose is to prevent the independence and stability of new States being endangered by fratricidal struggles provoked by the challenging of frontiers following the withdrawal of the administering power... Ibid.

37. http://www.oxfordbibliographies.com/view/document/obo9780199796953/obo-9780199796953-0065.xml 05/07/2018 16:50

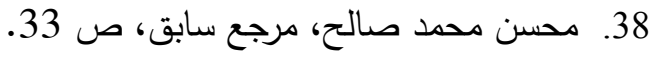

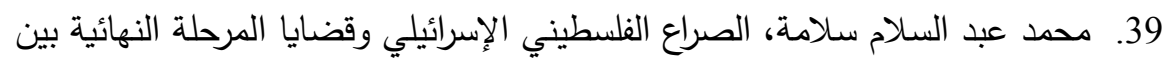

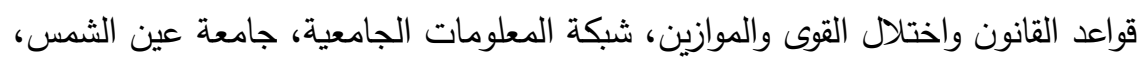

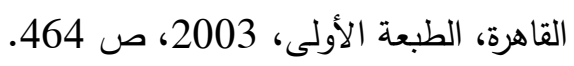

$$
\begin{aligned}
& \text { 40. عادل حامد الجادر، أثر قوانين الانتداب البريطاني في إقامة الوطن القومي اليهودي في }
\end{aligned}
$$

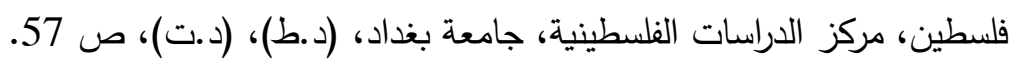

41. http://www.palestineinarabic.com/Docs/inter_arab_res/Palestine_B ritish_Mandate_1922_A.pdf 11/07/2018 $15: 50$

42. Musa E.Mazzawi, Palestine and the Law; Guidelines for the resolution of the arabe-israeli conflict, Ithaca press, 1997, First Edition, p241.

43. Op, cit, p 242.

44. Chemillier-Gendreau, Monique. « Jérusalem, le droit international comme source de solution », Confluences Méditerranée, vol. 86, no. 3, 2013, pp. 57-69.

45. Unscop : United Nations Special Committee on Palestine.

46. http://www.palestine-

studies.org/sites/default/files/UN_General_Assembly_Resolution_181.pd f $16 / 07 / 2018$ 16:02

$$
\begin{aligned}
& \text { 47. محد عبد السلام سلامة، مرجع سابق، ص 465. }
\end{aligned}
$$

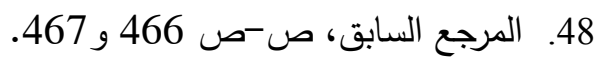

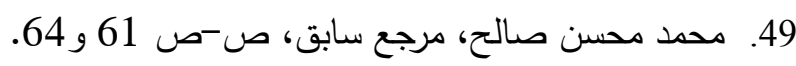




$$
\begin{aligned}
& \text { 50. موسى القدسي الدويك، مرجع سابق، ص } 13 .
\end{aligned}
$$

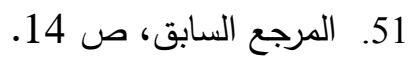

$$
\begin{aligned}
& \text { 52. بشير الشريف يوسف، فلسطين بين القانون الدولي والاتفاقيات الدولية، دار البداية، }
\end{aligned}
$$

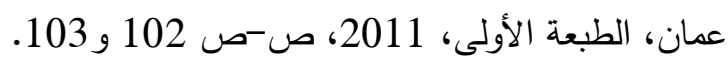

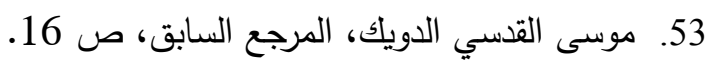

54. Musa E.Mazzawi, Op, Cit, P 248.

55. Op, Cit, P 250.

56. Monique Chemillier-Gendreau, Op, Cit, P 64.

$$
\text { 57. موسى القدسي الدويك، مرجع سابق، ص-ص 17و } 18 .
$$

58. Jhon Quingly, the case of Palestine on International Law

Prespective, Duke university press, durham \& London, revised and expanded Edition, 2005, p 213.

59.

Op, Cit, P 217

60. https://www.israelinarabic.com/بأورشليم-القس -عاصمة-لإسرائيل/

$16: 40$ 2018/07/18

61. https://www.nytimes.com/2017/12/06/world/middleeast/trumpjerusalem-israel-capital.html17:05 2018/07/18

62. http://www.bbc.com/arabic/world-4238815417:13 2018/07/18

$$
\begin{aligned}
& \text { 63. وفق القرار } 377 \text { لعام } 1950 \text { المعروف بقرار "الاتحاد من أجل السلام"، يمكن للجمعية }
\end{aligned}
$$

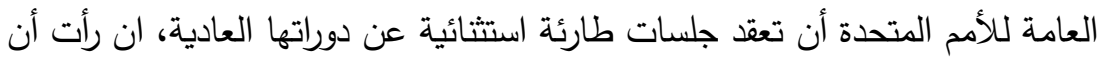

$$
\begin{aligned}
& \text { هنالك تهديد للأمن والسلم العالميين. }
\end{aligned}
$$

64. https://www.arab48.com/أخبار -عربية-ودولية/أخبار -

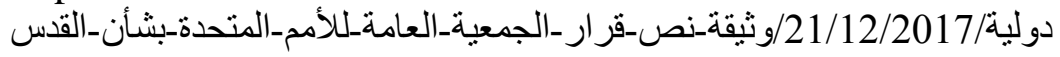
17:20 2018/07/18

65. https://www.dw.com/ar/-الكنيست-الإسرائيلي -يشدد-قيود-التخلي-عن -أي

$$
\text { 2018/07/18 }
$$

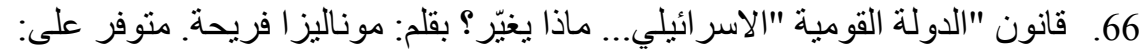

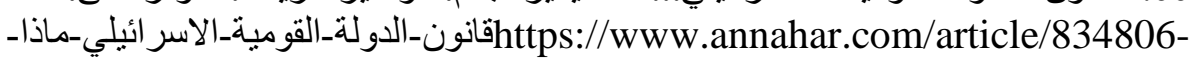
يغير 2018/07/23 16:00

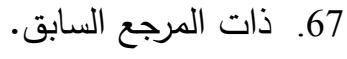

